\section{Preparation and application of cellular and nanoporous carbides $\dagger$}

\author{
Lars Borchardt, ${ }^{a}$ Claudia Hoffmann, ${ }^{a}$ Martin Oschatz, ${ }^{a}$ Lars Mammitzsch, ${ }^{b}$ \\ Uwe Petasch, ${ }^{b}$ Mathias Herrmann ${ }^{b}$ and Stefan Kaskel ${ }^{* a}$
}

\author{
Received 30th November 2011 \\ DOI: $10.1039 / \mathrm{c} 2 \mathrm{cs} 15324 \mathrm{f}$
}

\begin{abstract}
A tutorial review on cellular as well as nanoporous carbides covering their structure, synthesis and potential applications. Especially new carbide materials with a hierarchical pore structure are in focus. As a central theme silicon carbide based materials are picked out, but also titanium, tungsten and boron carbides, as well as carbide-derived carbons, are part of this review.
\end{abstract}

\section{Introduction}

Compounds of carbon with less electronegative elements are called "carbides". The following classes are known: salt-like (e.g. $\mathrm{CaC}_{2}$ ), covalent (e.g. $\left.\mathrm{SiC}\right)$, interstitial (e.g. TiC) and carbides with a more complex structure $\left(\right.$ e.g. $\mathrm{Fe}_{3} \mathrm{C}$ ). The chemical and physical properties of these classes differ significantly. This review will only focus on covalent and interstitial carbides and not on the highly reactive salt-like carbides.

In the year 1795 the term "carbide" was used for the first time by A. F. de Fourcroy in the Encyclopédie méthodique in analogy to the terms sulfide and phosphide. It was the time of the European Industrialisation, thus it is not astonishing that the first studies primarily focused on the iron carbon system. It took about one further century until first systematic investigations

${ }^{a}$ Department of Inorganic Chemistry, Dresden University of

Technology, Bergstraße 66, D-01069 Dresden, Germany.

E-mail:stefan.kaskel@chemie.tu-dresden.de;

Fax: + 49351463 37287; Tel: + 4935146333632

${ }^{b}$ Fraunhofer IKTS, Winterbergstraße 28, D-01277 Dresden, Germany.

E-mail: mathias.herrmann@ikts.fraunhofer.de;

Tel: +4935125537527

$\dagger$ Part of a web theme on the topic of nanomaterials (Deutsche

Forschungsgemeinschaft SPP1181/Nanomaterials program). were made on a wider spectrum of carbide materials. H. Moissan prepared and published 31 of these materials, including covalent carbides like silicon and boron carbides but also metal based carbides containing titanium or zirconium. It was the high hardness and high temperature stability that made these special materials valuable as abrasives and refractories. Nowadays, carbides are not solely used in structural elements but also in more advanced applications such as catalytic supports, filters, radiant burners, biomedical or electronic devices. A key issue for latter applications is to supply an increased specific surface area in order to enable optimal carbide-environment contact. Hence, a multiplicity of papers has been published over the last few decades dealing with different porous carbide materials, their preparation, characterization and applications. This review gives an overview about synthesis strategies towards porous carbides and selects remarkable examples. But also structural characteristics of the different carbides and promising applications are part of it. On one hand the class of macroporous cellular carbides is addressed and on the other hand a big issue is dedicated to the nanoporous carbides. Latter are mainly synthesized by hard- or soft templating approaches that often lead to materials with ordered pore symmetries that are important model systems in present day research. Thus, especially new carbide

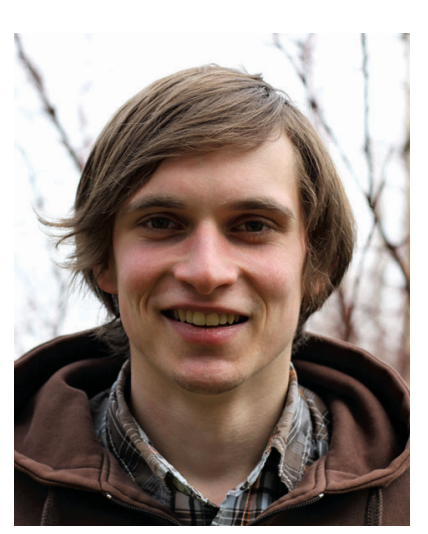

Lars Borchardt
Lars Borchardt studied chemistry at the Dresden University of Technology, where he received his diploma degree in 2009. He is currently working as a PhD student in the group of Prof. Dr Stefan Kaskel and focuses on the development of new porous carbon and carbide materials for energy storage applications.

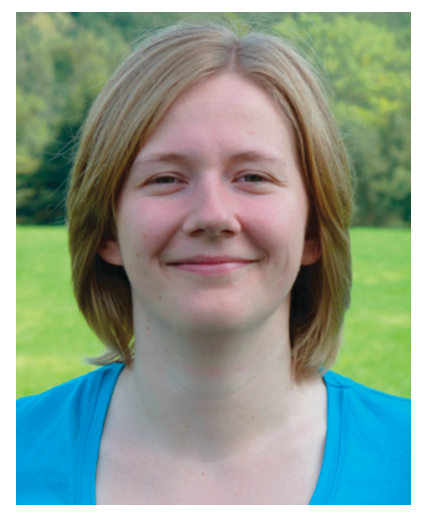

Claudia Hoffmann started studying chemistry at the Dresden University of Technology (TUD) in 2005 and received a BSc in 2008 as well as a MSc in 2010. She is currently pursuing her PhD in the group of Prof. Stefan Kaskel at TUD. Her interests are high-temperature stable catalysts and catalyst supports (e.g. silicon carbide). 
materials with a hierarchical pore structure are in focus. As a central theme silicon carbide based materials are picked out, but also titanium, tungsten and boron carbides, as well as carbide derived carbons, are part of this review.

\section{Structure}

Carbide ceramics play an increasing role both as structural and as functional materials. They exhibit exceptional properties such as high hardness, wear resistance, high strength and creep resistance at high temperatures as well as high corrosion resistance. Silicon carbide and boron carbide materials are the most important carbide ceramic materials. Materials based on transition metal carbides are usually not included in the class of ceramic materials. They are the basis of so called cermets (ceramic cubic carbides and nitrides of the transition metals (groups IVb-Vb) or hard metals bound with metals (usually $\mathrm{Ni}, \mathrm{Co}, \mathrm{Fe}$ )). Table 1 summarizes the crystal structures and some properties of carbides mentioned in this tutorial review.

However, many properties strongly depend on the production method, i.e. the strength and fracture toughness of liquid phase sintered silicon carbide materials can be two times higher than the values of solid phase sintered. The porosity also strongly influences the mechanical and thermal properties. Detailed descriptions of the production methods and their influence on the properties are given in the review. ${ }^{1}$ The exceptional properties of carbides are mostly connected to their strong, predominantly covalent chemical bonds and the crystal structure (Fig. 1). These bonds form a three dimensional network in SiC. Silicon carbide exists in a cubic modification $(\beta-\mathrm{SiC})$ and as hexagonal or rhombohedral polytypes $(\alpha-\mathrm{SiC})$. The cubic structure is present at temperatures below $1800{ }^{\circ} \mathrm{C}$, and the polytypes are formed at higher temperatures. The structure of

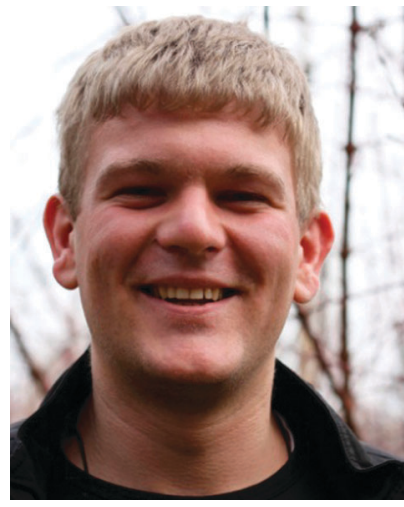

Martin Oschatz studied chemistry at the Dresden University of Technology (TUD) from 2006 to 2011 and received $a$ BSc in 2009 as well as a MSc in 2011. He is currently pursuing his PhD in the group of Prof. Stefan Kaskel at TUD. Porous carbon materials for gas and energy storage applications are the main objectives of his research.

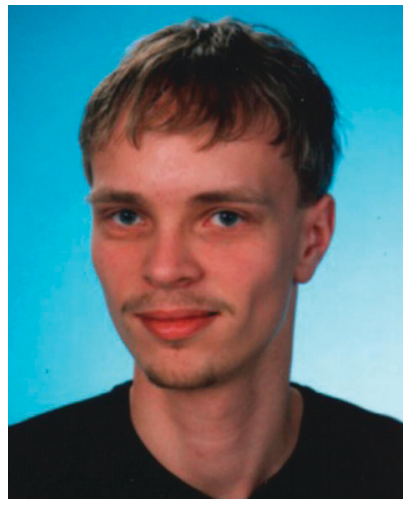

Lars Mammitzsch

Lars Mammitzsch was born in Leipzig, Germany, in 1981. He studied chemistry and wrote his diploma thesis in the field of heterogeneous catalysis at the Technical University of Dresden in 2006. After one year work experience in the field of electroplating he began his PhD studies at the Fraunhofer Institute for Ceramic Technologies and Systems IKTS in Dresden in the division of carbide and filter ceramics in 2008. His research concentrates on catalytic applications for porous ceramic materials for exhaust after treatment.

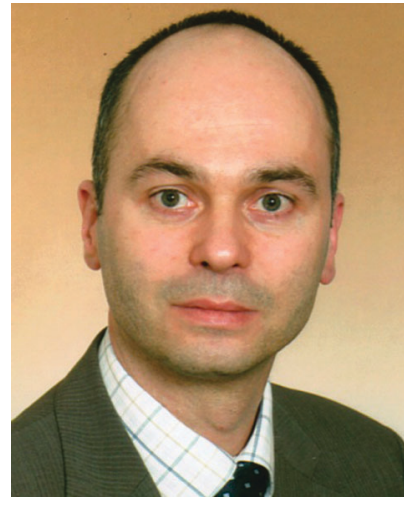

Uwe Petasch
Uwe Petasch was born near Kamenz, Germany, in 1968. He studied chemistry and wrote his PhD thesis in the field of inorganic solid state chemistry at the Technical University of Dresden. In 1999, he began to work at the Fraunhofer Institute for Ceramic Technologies and Systems IKTS in Dresden. Today, he is working in the carbide and filter ceramics division of the institute. His research concentrates on porous ceramic materials in filtration and catalytic applications with a particular focus on materials for exhaust after treatment.

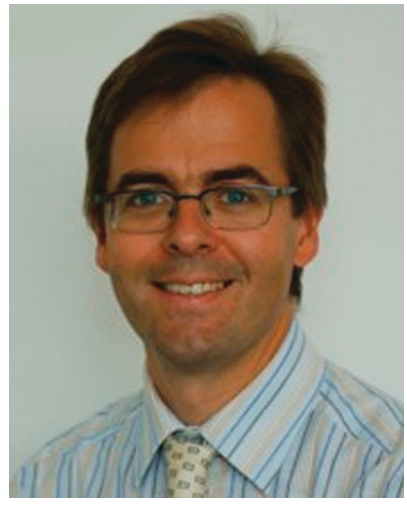

Stefan Kaskel
From 1990 to 1995, Prof. Dr Stefan Kaskel studied chemistry in Tübingen. In 1997, he obtained his PhD degree from Eberhard-KarlsUniversität Tübingen working on in situ powder diffraction. After a post-doctoral stay as a Feodor Lynen fellow of the Alexander von Humboldt foundation in the working group of J. D. Corbett, Ames Laboratory (DOE) and Iowa State University, Ames, Iowa, he obtained his habilitation degree in 2003 at Bochum University on the design and functionality of new porous materials when he also worked as a group leader at the Max Planck Institute for Coal Research from 2002 to 2004. Since June 2004, he is Professor of Inorganic Chemistry at Dresden University of Technology and, from 2008 on, also head of department of thin-film technology at the Fraunhofer Institute for Material and Beam Technology (IWS), Dresden. 
Table 1 Structure parameters and physical properties of some carbides

\begin{tabular}{|c|c|c|c|c|c|c|c|c|c|}
\hline Compound & Symmetry & Space group & $a^{a}$ & $c^{a}$ & Density $^{b}$ & $T_{\mathrm{m}}{ }^{c}$ & $\alpha^{d}$ & Young's modulus ${ }^{e}$ & Micro-hardness ${ }^{e}$ \\
\hline$\beta-\mathrm{SiC}$ & Cubic & 216 & 4.3589 & & 3.216 & \multirow{6}{*}{2545} & \multirow{6}{*}{$\begin{array}{l}4.5 \\
4.5\end{array}$} & \multirow{6}{*}{$\begin{array}{l}400 \\
440\end{array}$} & \multirow{6}{*}{$\begin{array}{l}20-30 \\
20-30\end{array}$} \\
\hline$\alpha-\mathrm{SiC}$ & & & & & & & & & \\
\hline $2 \mathrm{H}$ & Hex. & 186 & 3.081 & 5.031 & 3.22 & & & & \\
\hline $4 \mathrm{H}$ & Hex. & 186 & 3.081 & 10.061 & 3.22 & & & & \\
\hline $6 \mathrm{~h}$ & Hex. & 186 & 3.073 & 15.080 & 3.22 & & & & \\
\hline $15 \mathrm{R}$ & Rhom. & 160 & 3.073 & 37.700 & 2.24 & & & & \\
\hline $\mathrm{B}_{4+x} \mathrm{C}$ & Rhom. & 160 & & 12.074 & 2.52 & $2350-2470$ & 4.5 & 450 & $37-45$ \\
\hline WC & Hex. & 187 & 2.906 & 2.838 & 15.67 & $2600-2880$ & 5.3 & $690-720$ & $21-25$ \\
\hline $\mathrm{TiC}$ & Cubic & 225 & 0.4327 & & 4.91 & $3070-3150$ & 7.4 & 450 & $24-32$ \\
\hline \multicolumn{9}{|c|}{${ }^{a}[\AA] .{ }^{b}\left[\mathrm{~g} \mathrm{~cm}^{-3}\right] \cdot{ }^{c}\left[{ }^{\circ} \mathrm{C}\right] \cdot{ }^{d}\left[10^{-6} \mathrm{~K}^{-1}\right] \cdot{ }^{e}[\mathrm{GPa}]}$. & \\
\hline
\end{tabular}

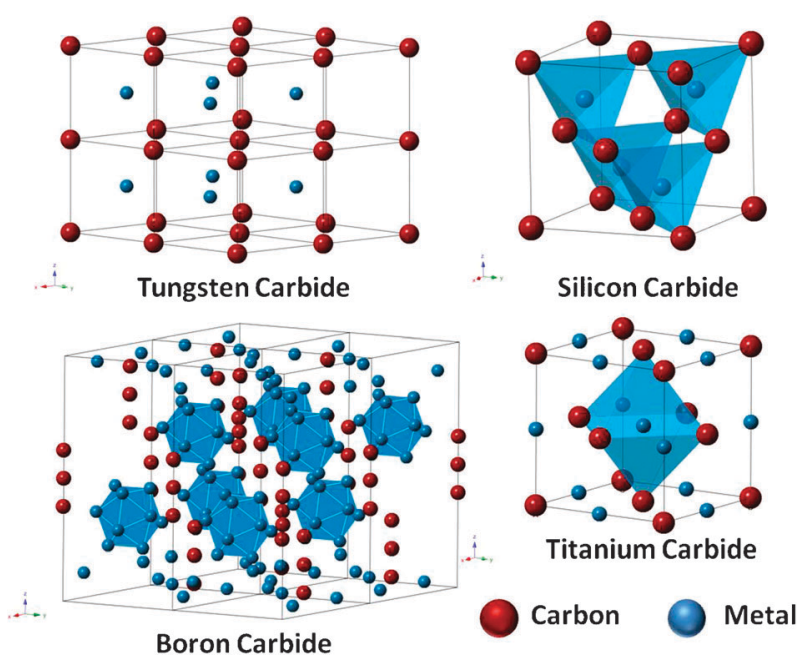

Fig. 1 Crystal structure of discussed carbides (atom sizes are not true to scale).

the cubic $\mathrm{SiC}$ can be derived from the diamond structure by replacing every second carbon atom by a silicon atom (zinc blende structure). The structures of the hexagonal or rhombohedral polytypes can be imagined from the cubic structure by a regular shift of layers perpendicular to the initial diagonal of the cubic unit cell of $\beta-\mathrm{SiC} .{ }^{1}$ All the polytypes are formed by corner-sharing tetrahedra resulting in a three dimensional network. Both carbon and silicon have the coordination number of four in the crystal structures resulting in high elastic constants and hardness. ${ }^{1}$ Boron carbide forms a structure based on $\mathrm{B}_{12}$ icosahedral polyhedrons linked by three atom bridges. The boron in $\mathrm{B}_{12}$ can be partially replaced by carbon and also bridges between the $\mathrm{B}_{12}$ units can have different boron-carbon ratios. Therefore, boron carbide has a quite large homogeneity range $\left(\mathrm{B}_{12} \mathrm{C}-\mathrm{B}_{4.3} \mathrm{C}\right){ }^{1}$ Most of the important transition metal carbides (e.g. $\mathrm{Ti}, \mathrm{Zr}, \mathrm{Hf}, \mathrm{Nb}$ ) crystallize in a cubic $\mathrm{NaCl}$ structure where the metal atoms have a cubic close-packed arrangement. ${ }^{1}$ The carbon is located in the octahedral sites between the metal atoms. These compounds normally have a wide homogeneity range and exhibit a metallic conductivity. The other important transition metal carbide, WC, exhibits a hexagonal crystal lattice and does not exhibit a homogeneity range.

Non-oxide ceramics are not in chemical equilibrium in air and can react with oxygen forming oxides. ${ }^{2}$ Due to the formation of a protecting oxide layer the materials are stable in air. The stability strongly depends on the properties of the oxide.
The silicon based ceramics form a silica layer which has very low oxygen diffusion coefficients even at high temperatures. Therefore, these materials can be stabilized up to temperatures of $1600{ }^{\circ} \mathrm{C}$. Boron carbide or the transition metal carbides form a less protecting oxide layer resulting in much lower stability at high temperatures. This has to be taken into account, especially when these materials are used at higher temperatures in air.

\section{Synthesis}

A high degree of porosity is a key issue for numerous applications. In the following, approaches for the generation of porosity in carbide materials will be addressed. In general two classes of porous materials should be distinguished: (i) cellular materials usually with pores in the $\mu \mathrm{m}$-scale, and (ii) nanoporous materials covering micro- and mesoporosity. While the materials considerably differ in their manufacturing techniques (soft templating, hard templating or etching approaches etc.), they have in common that they are either derived by carbothermal reduction of (semi-)metal oxides by carbonaceous species, or from preceramic polymer precursors already containing the ceramic backbone in their molecular structure.

Carbothermal reduction approaches ${ }^{3}$ are industrially well established since the starting materials are comparably low by cost. However, high temperatures are required for this highly endothermic reaction. Nevertheless, in the case of silicon carbide this process is the main industrial route for the production of $\mathrm{SiC}$ powder (Acheson process). Eqn (1) typifies the overall reaction.

$$
\mathrm{SiO}_{2}(\mathrm{~s})+3 \mathrm{C}(\mathrm{s}) \Rightarrow \mathrm{SiC}(\mathrm{s})+2 \mathrm{CO}(\mathrm{g})
$$

It is generally accepted that $\mathrm{SiC}$ is formed via a gaseous $\mathrm{SiO}$ intermediate (eqn (2) and (3)), subsequently reacting with solid carbon (eqn (4)).

$$
\mathrm{SiO}_{2}(\mathrm{~s})+\mathrm{C}(\mathrm{s}) \Rightarrow \mathrm{SiO}(\mathrm{g})+\mathrm{CO}(\mathrm{g})
$$

The Gibbs free energy of the overall reduction reaction (eqn (1)) becomes negative at about $1793 \mathrm{~K}$ ( 1 bar), illustrating the minimum temperature to promote the reaction with reasonable rates.

$$
\begin{gathered}
\mathrm{SiO}_{2}(\mathrm{~s})+\mathrm{CO}(\mathrm{g}) \Rightarrow \mathrm{SiO}(\mathrm{g})+\mathrm{CO}_{2}(\mathrm{~g}) \\
\mathrm{SiO}_{2}(\mathrm{~g})+2 \mathrm{C}(\mathrm{s}) \Rightarrow \mathrm{SiC}(\mathrm{s})+\mathrm{CO}(\mathrm{g})
\end{gathered}
$$

With the development of organoelement chemistry in the last century considerable attention was pointed to precursors 


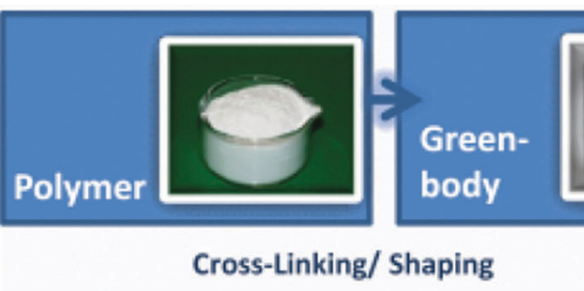

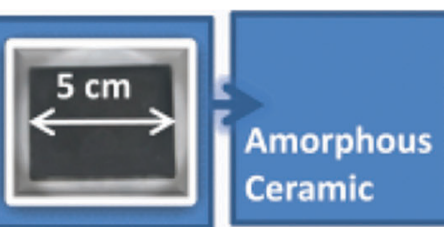

Pyrolysis $1100^{\circ} \mathrm{C}$

Fig. 2 Steps of the transformation from a preceramic polymer to a polymer-derived ceramic (PDC) picture are reprinted with permission from ref. 4.

for the synthesis of ceramic materials. Ceramics obtained from those polymer precursors are therefore known as polymerderived ceramics (PDCs). ${ }^{4}$ The synthesis usually undergoes four steps. After designing a precursor polymer from monomer units, it is cross-linked in the desired 1D- (fibres), 2D- (coatings, membranes) or 3D- (monolith, powder) shape. Afterwards, the network is transformed into the amorphous covalent ceramic and subsequently crystallized to the thermodynamically stable phase (Fig. 2). This procedure has a number of advantages: (i) the defined molecular structure facilitates the total control over structure and properties of the final ceramic, mostly superior to that of conventionally derived ceramics, (ii) any kind of shape can be obtained during processing, ranging from fibres to coatings or even complex ordered structures, (iii) the fact that the polymer backbone already contains the final metal-carbon connectivity results in a significant lowering of the minimum synthesis temperatures.

The majority of polymer precursors described so far are set by those containing silicon, such as polysiloxanes, polysilazanes, polycarbosiloxanes or polycarbosilanes, but there are also several studies using polyborazines, polytitanocarbosilanes or polyaluminocarbosilanes (Fig. 3). ${ }^{4}$ Disadvantages of this method for the preparation of bulk materials are high volume changes and the formation of a large amount of gaseous products during ceramic conversion. However, this can be neglected if coatings or porous materials are prepared. Another strategy to overcome this difficulty is to use active fillers which react with the gaseous species forming carbides.

\subsection{Cellular materials}

The class of cellular materials covers a wide spectrum of different structures, such as foams and honeycombs as well as different kinds of interconnected units, such as fibres, hollow spheres, or rods. Moreover, a variety of cellular materials can be found in nature (e.g. wood, coral, sponge, lung). They all have in common that they contain a high porosity $(>60 \%)$ and a recognizable cell, defined as an empty space or identifiable geometry enclosed by faces and solid edges (struts). Basically there are two different kinds of cells, closed and open cells, with either fully solid or void faces. Owing to their special structure, cellular ceramics combine a variety of interesting properties, such as high porosity and high surface area, low density and low thermal conductivity, high permeability, high thermal shock resistance, high specific strength and high resistance to chemical corrosion. Applications for cellular materials are likewise numerous, covering catalyst supports, filtration of gases and liquids, biomedical and electrochemical devices, thermal protection systems and heat exchangers.

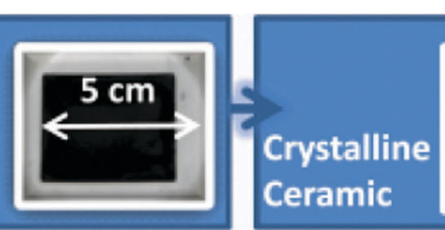

Thermal Treatment $1500-2000^{\circ} \mathrm{C}$

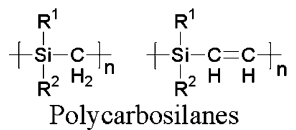<smiles>[R][V]([R])(Cl)CCCC</smiles>

Polysiloxanes

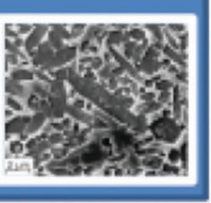

$\mathrm{R}^{1}$
$+\mathrm{S}^{\mathrm{S}}-\mathrm{N}+{ }_{\mathrm{n}}$
$\mathrm{R}^{2} \mathrm{H}$

Polysilazanes

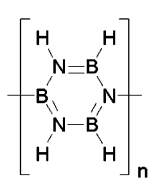

Polyborazines
$R^{1}$

$+\underset{1}{\mathrm{Si}-}-\mathrm{C}+\mathrm{H}_{2}{ }_{\mathrm{n}}$

$\mathrm{R}^{2}-\mathrm{O}-\frac{\mathrm{I}}{\mathrm{Ti}}-\mathrm{O}-\mathrm{R}^{2}$

$\stackrel{\circ}{R^{2}}$

Polytitanocarbosilanes

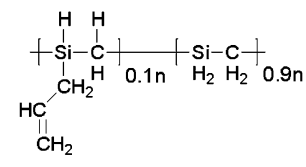

Allylhydridopolycarbosilanes

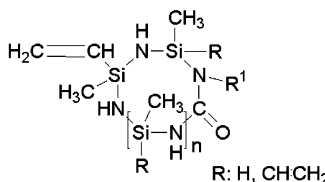

Polyureamethylvinylsilazane

(Ceraset)
Fig. 3 Selection of polymer precursors for PDCs.

Nevertheless, the specific application strongly depends on the layout and thus the particular processing approach of the cellular material. A detailed review about the processing of cellular ceramics was given by Colombo. ${ }^{5}$

Several aspects are crucial if a cellular material is designed, mainly the size and size distribution of the cells, the connection of the cells due to voids and windows, the total porosity and density of the material, the constitution of the cell walls with respect to thickness and orientation and last but not least the overall cost of the processing method.

The majority of industrially fabricated cellular materials are set by the group of foams and three main synthesis strategies (Fig. 4) can be differentiated. In the first strategy (path I) a flexible polymeric pre-foam, usually made of polyurethane, polystyrene, cellulose, latex, etc., is used as a template and is impregnated with a ceramic slurry. After drying, the polymer template is burned out and the ceramic is sintered. Obtained materials are called reticulated ceramics. First, it has to be considered that the composition of the slurry is of huge importance since attractive interactions between the template and the slurry have to be ensured. Therefore optimized binders and rheological agents are essential. Besides, the incomplete removal of excess slip after the impregnation process may cause the presence of a small amount of closed cells in the final ceramic. Furthermore, temperature treatment must be performed with moderate heating ramps in order to avoid stresses and defects in the final ceramic. Finally, a compulsive consequence of the polymer-burning step is the insertion of cavities inside the struts. This is not necessarily a disadvantage but has to be 


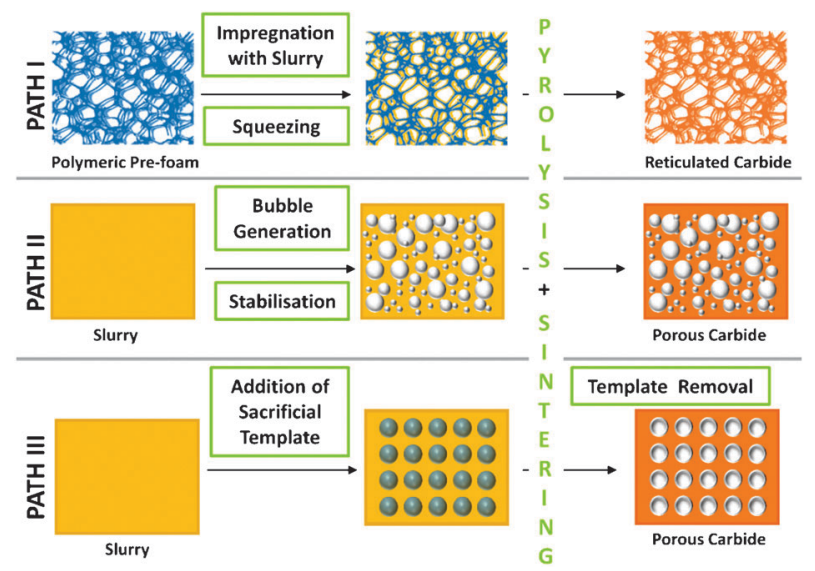

Fig. 4 Different synthesis strategies towards cellular carbide materials.

considered if this approach is used. In some cases this attended mass reduction is even favoured. Nevertheless, there exist several methods to fill these struts in order to increase the strength of the ceramic foam. The second strategy (path II) describes the direct foaming due to bubble evolution in liquid preceramic slurries. A very obvious idea is the gas injection during mechanical stirring of the slurry. Further attempts generate the blowing agent in situ by adding volatile liquids or decomposable solids (e.g. $\mathrm{CaCO}_{3}$ ) to the ceramic precursor. Gaseous blowing species can also be formed due to chemical reactions, such as cross-linking, leading to gaseous $\mathrm{H}_{2} \mathrm{O}, \mathrm{H}_{2}$, etc. To finally maintain the porous morphology of the ceramic, the preceramic precursor solution needs to be set, otherwise gas diffusion among the bubbles will lead to the growth of large bubbles and the shrinkage of smaller ones (Ostwald ripening). This would result in increased cell sizes or even film rupture. Thus the green precursor solution has to be stabilized by different strategies, such as polymerization of organic monomers, agglutinating with proteins, starch or cellulose derivates, cross-linking reactions or freezing. Foams obtained by this approach (path II) differ from reticulated foams (path I) in some aspects such as the presence of both, closed and open cells, whereas reticulated ceramics primarily exhibit open cells. Furthermore, pore size distributions are broader and average pore sizes are likewise larger in directly foamed ceramics. In contrast the pore volume is mostly lower than that of reticulated ceramics. Different expansion rates of the bubble agent in the rise direction versus the lateral ones often lead to graded structures. However, struts of directly foamed ceramics are dense leading to improved mechanical strength compared to reticulated foams. The direct foaming method is able to produce complex parts, either by shaping in moulds or by machining of ceramic foams.

The third approach (path III) uses sacrificial templates, serving as a placeholder during shaping of the preceramic slurry. Several of these fillers (that in contrast to path I do not have a foamed shape) are described in the literature reaching from different polymers such as poly(methyl methacrylate), polystyrene, wax and starch to carbons, silica or sawdust. The main advantage using sacrificial templates is the precise control over total porosity, the amount of open and closed pores as well as the final pore shape. Thus the used filler is essential for the properties of the resulting foam. The removal of the sacrificial templates by pyrolysis, evaporation or sublimation is the critical step during the production of components. These processes involve the removal of high amounts of gases, which have to be homogeneously carried out from the volume of the component to avoid cracking of the cellular structure.

In contrast to the cells of foams (path I to path III) which are usually randomly oriented in space, honeycombs have parallel unidirectional prismatic cells. Traditionally they are manufactured by extrusion of ceramic feedstock, followed by drying, debinding and sintering. The main advantages of honeycombs are low backpressure and high structural strength, being particularly important for catalytic applications. The cell shape can be adjusted from a triangular, square, circular to a hexagonal cross-section. Besides this, components with large dimensions and high precision of cells can easily be manufactured.

In recent years, the replication of biological structures such as wood has received considerable attention, since they are abundantly available and cost efficient. Usually the wooden template first has to be converted into the carbonaceous analogue via pyrolysis under inert atmosphere. After a preceramic precursor, such as $\mathrm{Si}$, gaseous $\mathrm{SiO}$ or colloidal silica, is infiltrated the carbon template is converted into the carbide. The hierarchical pore structure of the wooden template, ranging down to the nanometre scale, is thus transformed into the ceramic. Disadvantages of the wood-replica approach for a reproducible production of components are the high degree of variety in biological structures, the high amount of impurities and the huge and inhomogeneous shrinkage during pyrolysis.

There are a variety of other fabrication approaches, like additive manufacturing technologies (AMT), the sintering of hollow spheres, connected rods or fibres. For further particulars the authors refer you to the reviews written by Colombo et al. ${ }^{5,6}$ and Greil et al. ${ }^{7}$

Silicon carbide based materials. The carbothermal reduction of silica with carbon has been the most prevalent procedure for synthesizing silicon carbide materials for a long time. In the last few years however, preceramic polymers like polysiloxanes or polycarbosilanes induced a growing interest. Recently, macroporous $\mathrm{SiOC}$ ceramics have been synthesized via one-step pyrolysis of silicone precursors. It has been shown that the use of a mixture of silicone precursors with different molecular architectures can tailor the resulting pores in a range from a few to hundreds of microns. ${ }^{8}$

Furthermore, highly aligned, porous $\mathrm{SiC}$ with well-defined pore structure has been obtained from freezing polycarbosilanecamphene solutions (Fig. 5A). After a thermally induced phase separation of this system the resulting bicontinuous structure can be transferred to the porous ceramic by removing the camphene phase using freeze drying and subsequent pyrolysis at $1673 \mathrm{~K}$. The freezing temperature strongly influences the cell size in the range of 2.5 to $25 \mu \mathrm{m}$. $^{9}$

However, to provide advanced functionality for applications in catalysis, extraction, separation or adsorption, a secondary porosity of smaller pores is often required. Such hierarchical carbides can be obtained either by a dual-step route (post-synthetic etching, post-synthetic coating with mesoporous films, etc.) or by a single-step strategy. The latter was recently performed 

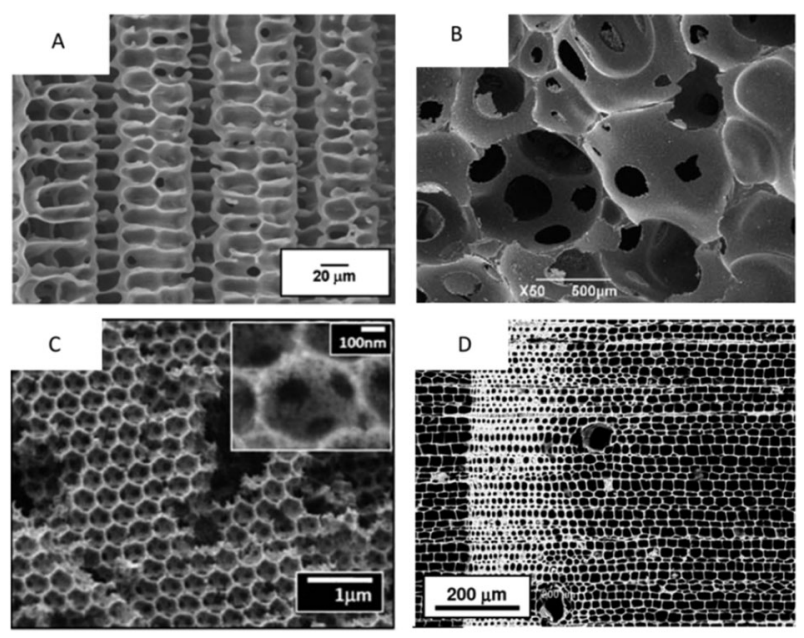

Fig. 5 SEM images of macroporous $\mathrm{SiC}$ derived from a freeze drying approach $^{9}(\mathrm{~A})$, hierarchical $\mathrm{SiCN}^{12}$ (B), 3D ordered macroporous $\mathrm{WC}^{13}$ (C) and wood derived microcellular titanium carbide ${ }^{15}(\mathrm{D})$, pictures are reprinted with permission from ref. 9, 12, 13 and 15 .

by embedding periodic mesoporous organosilicas (PMOs) in foamed siloxane preceramic polymers.

Ceramic conversion led to open cell foams with a secondary mesoporosity. These ceramics have specific surface areas of up to $137 \mathrm{~m}^{2} \mathrm{~g}^{-1}$ combined with compressive strength values (1.7 MPa), making them suitable for many engineering applications. ${ }^{10}$

Hierarchical $\mathrm{SiC}$ ceramics have recently been synthesized by Smarsly and co-workers. They used a preformed $\mathrm{SiO}_{2}$ framework which was coated with a graphite precursor and has subsequently been transformed into $\mathrm{SiC}$ ceramic via carbothermal reduction. Obtained materials exhibit a hierarchical pore network of meso- $(13 \mathrm{~nm})$ and macropores $(2-6 \mu \mathrm{m})$ and show specific surface areas of up to $280 \mathrm{~m}^{2} \mathrm{~g}^{-1}$ and pore volumes of $0.8 \mathrm{~cm}^{3} \mathrm{~g}^{-1} .11$

In a similar way highly porous $\mathrm{SiCN}$ and $\mathrm{SiOCN}$ foams (porosity 60-80\%) were synthesized by Colombo and co-workers by using polysilazanes (Ceraset) as preceramic precursors (Fig. 5B). ${ }^{12}$ These liquid polymers were either mixed with the physical blowing agent azodicarbonamide (path II) or with the sacrificial filler poly(methyl methacrylate) (PMMA) (path III). This demonstrates the importance of the used approach on the properties of the final ceramic foam. Microcellular materials (cell size $15 \mu \mathrm{m}$ ) were obtained by using pathway II whereas pathway III resulted in macrocellular ceramics. All materials exhibit an interconnected pore network and compressive strength in the range of 1 to $11 \mathrm{MPa}$.

Transition metal carbides. WC has gained considerable attention as a substitute for the expensive platinum catalyst in fuel cell applications. Three dimensional ordered macroporous WC has recently been synthesized using PMMA colloidal crystal templates with diameters from 180 to $490 \mathrm{~nm}$ (Fig. 5C). In a first step these spheres were impregnated with tungsten, and subsequently calcined and carburized leading to WC materials with uniform macropore sizes as well as secondary mesopores, mainly contributed to excess carbon. ${ }^{13}$

There are only a few reports about the synthesis of cellular titanium or zirconium carbides in current literature. Mainly wood templating approaches have been used for the synthesis of those metal carbide/carbon composites. Sieber et al. infiltrated organometallic colloidal suspensions into pine wood derived carbon templates. After conversion to the corresponding metal oxide these materials are finally carbothermally reduced to the metal carbide. The initial porosity of the biocarbon template and the amount of infiltrated preceramic precursor are crucial for the conversion ratio of metal oxide to metal carbide. In this case yields of only $6 \% \mathrm{TiC}$ or $\mathrm{ZrC}$ phase have been obtained. ${ }^{14}$ Higher conversion ratios were achieved by chemical vapour infiltration of $\mathrm{TiCl}_{4} / \mathrm{H}_{2}$ into wood derived carbon templates (Fig. 5D). If nitrogen is added to the infiltration vapour, TiCN type materials may be obtained. ${ }^{15}$

\subsection{Nanoporous materials}

In the following, methods for the synthesis of porous carbides with pore sizes below $100 \mathrm{~nm}$ will be addressed. Even though the traditional IUPAC recommendation would group these materials into micro- and mesoporous materials with pores $d<2 \mathrm{~nm}$ and $d=2-50 \mathrm{~nm}$, the term nanoporous $(d<100 \mathrm{~nm})$ is nowadays widely accepted and is currently under revision in a new IUPAC commission. It should also be emphasized that most of the materials have been addressed so far have only been synthesized as powders and not as monolithic materials. Such compact bodies of nanoporous materials would require a secondary hierarchical architecture in order to avoid mass transport limitations in their application.

3.2.1 Hard templating approaches. The hard template concept (also known as nanocasting) can be compared with a moulding process, which is adapted from the macro- to the nanoscale. Thereby a solid template acts as a "casting mould" or rather as a space confinement in which a precursor is transferred into the desired product (Fig. 6). Using this strategy, the void architecture is obtained as a solid network being an inverse replica of the used template. If this template already exhibits a periodic structure this regularity can be conserved and the replica is then called "ordered". Primarily carbons and silicas are used as templates such as ordered mesoporous silicas (e.g. SBA-15 and KIT-6) and ordered mesoporous carbons

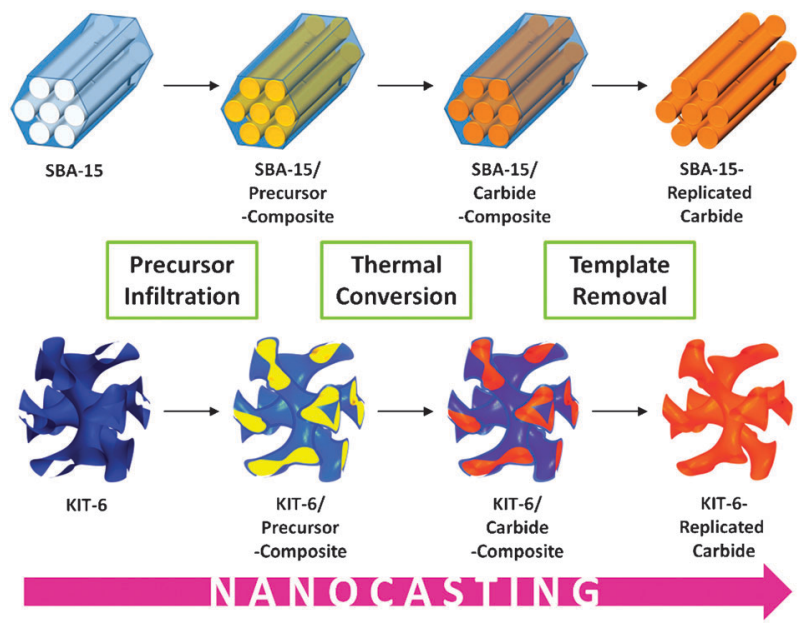

Fig. 6 Hard templating approaches (nanocasting) exemplified for hexagonal and cubic silica templates. 
(e.g. CMK-3 and CMK-8). However, a wide variety of nonordered templates such as activated carbons, silica nanospheres, or silica monoliths may be used as well. Ordered nanoporous materials can be divided into different classes with respect to the pore ordering. 2D-hexagonal (e.g. SBA-15, CMK-3) and 3D-cubic (e.g. KIT-6, CMK-8) ordering are the most common. The replication of those systems is challenging mainly due to three reasons: (i) the volume shrinkage of precursors, (ii) the volatility of precursors or synthesis intermediates, and (iii) the difficulty to preserve the ordering of the templates during thermal treatments in the nanocasting process. The first aim in hard templating approaches is typically the complete infiltration of the template pores with the precursor. If a liquid precursor is used, it can be infiltrated directly. However, many precursors are solid and thus have to be infiltrated either via melt infiltration or dissolved in appropriate solvents.

Such solvents have to be removed consequently reducing the overall degree of pore filling. In the latter case several impregnation steps are necessary to exploit all the voids. Independent of the physical conditions of the precursor and the insertion routine, often shrinkage is observed during thermal transfer into the desired product. This sometimes inhibits good replication and the conservation of the ordered structure. Hence, it is essential to use precursors, causing only little shrinkage during conversion into the carbide material. This circumstance also points out that the choice of the precursor is limited. To avoid precursor migration out of the template pores during thermal conversion, precursors that are not volatile under reaction conditions should be used. This effect plays a crucial role in carbothermal reduction processes where gaseous intermediates (e.g. $\mathrm{SiO}$ ) are formed. The preservation of the $3 \mathrm{D}$ shape during replication is dependent on the detailed structure of the used template. According to Fig. 6, silica templates such as SBA-15 or KIT-6 consist of a 2D-hexagonal ordered or a bicontinuous gyroid mesopore system. An additional secondary micropore connectivity between these mesopores is present and is filled in the nanocasting process, thus stabilizing the structure during the replication process. Without these connections the replication of SBA-15 would afford loose rods and that of KIT- 6 would possess a symmetry reduction of the pore network. ${ }^{16}$ However, the presence of these micropores enables a symmetry equivalent replication of SBA-15 and KIT- 6 templates.

In principle two major classes of hard-templates can be distinguished, those which are part of the chemical reaction, subsequently forming the desired product (sacrificial template), and those which simply act as a place holder and therefore have to be removed afterwards in order to obtain the nanoporous carbide. In cases of silica templates the desired removal is mainly conducted with HF solution. Carbon templates are removed by oxidation in air or reduction with ammonia. Thus, ceramics achievable via hard templating routes are further limited due to stability issues against hydrofluoric acid, oxidizing or reducing conditions. More examples of nanocasting approaches and nanoporous non-oxide materials were reviewed recently. ${ }^{17,18}$

Silicon carbide based materials. The first concept for the synthesis of mesoporous silicon carbide by chemical vapour infiltration of ordered mesoporous silicas (MCM-48 and SBA-15)

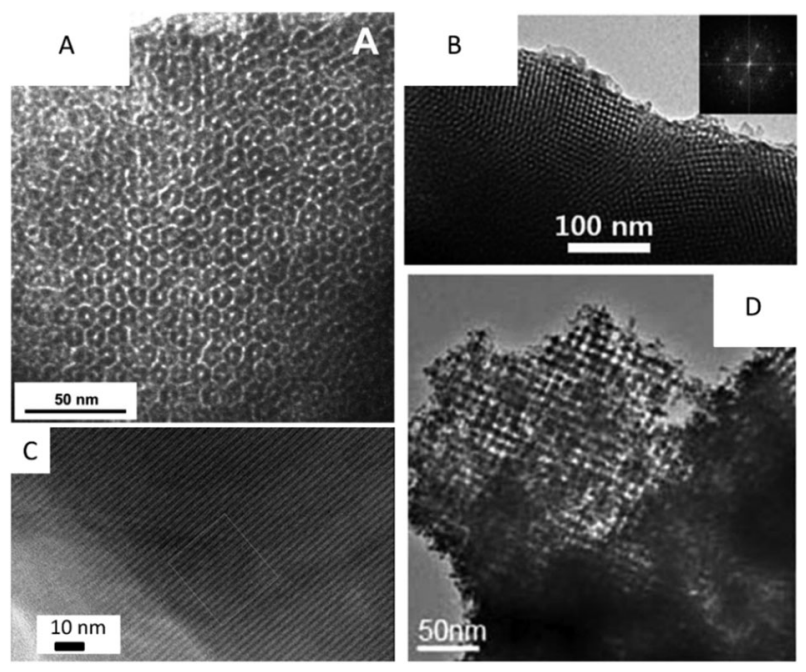

Fig. 7 TEM images of ordered mesoporous $\mathrm{SiC}$ with tubular structure ${ }^{16}$ (A), ordered mesoporous $\mathrm{C}_{3} \mathrm{~N}_{4}{ }^{29}(\mathrm{~B})$, ordered mesoporous $\mathrm{B}_{4} \mathrm{C}^{31}(\mathrm{C})$, and ordered mesoporous $\mathrm{WC}^{32}(\mathrm{D})$ pictures are reprinted with permission from ref. 16, 29, 31 and 32 .

was proposed in 2004. ${ }^{19}$ Dimethyldichlorosilane was infiltrated into the mesoporous network of the silica matrices at $1023 \mathrm{~K}$ and $1163 \mathrm{~K}$ in hydrogen atmosphere for the deposition of SiC. After dissolution of SBA-15 only disordered silicon carbide was obtained, nevertheless the material had a surface area of $508 \mathrm{~m}^{2} \mathrm{~g}^{-1}$ and a pore volume of $0.96 \mathrm{~cm}^{3} \mathrm{~g}^{-1}$. In the following years ordered mesostructures have been realized by the use of polycarbosilanes. For instance, SBA-15 and KIT-6 were replicated resulting in $\mathrm{SiC}$ with surface areas of nearly $1000 \mathrm{~m}^{2} \mathrm{~g}^{-1} \cdot{ }^{16}$ Next to these rod-like structures also hexagonally ordered mesoporous silicon carbide with a tubular structure (CMK-5 analogue) was synthesized by tuning the precursor wetting and infiltration (Fig. 7A). ${ }^{16}$ Furthermore, silica spheres from a commercial silica sol ${ }^{20}$ and a mesoporous siliceous foam MCF- $5^{21}$ were successfully replicated.

All these strategies require the removal of the hard template after thermal conversion of the preceramic precursor. However there are some reports about the direct carbothermal reduction between the silica template and carbon (usually generated from the infiltration of furfuryl alcohol or sucrose). By using ordered mesoporous SBA-15 templates porous $\mathrm{SiC}$ has been obtained with an ordered mesopore arrangement and surface areas of $159 \mathrm{~m}^{2} \mathrm{~g}^{-1} \cdot{ }^{22}$ Furthermore Leventis et al. have used polyacrylonitrile to form an aerogel with silica particles resulting in a hereby stabilized architecture. ${ }^{23}$ The polyacrylonitrile was subsequently converted into carbon in situ followed by carbothermal reduction. To lower the desired temperature for the synthesis of silicon carbide via carbothermal reduction ( $>1795 \mathrm{~K}$ ), Zhao et al. recently demonstrated the magnesiothermic reduction approach. ${ }^{24}$ This method allows the fabrication of mesoporous $\mathrm{SiC}$ at temperatures as low as $923 \mathrm{~K}$. The mechanism was described as follows. Magnesium reduces silicon dioxide to silicon which further reacts with the carbon to form silicon carbide. Additionally, magnesium acts as a catalyst for the reaction between $\mathrm{Si}$ and $\mathrm{C}$. The latter approaches can be inverted and carbon templates like CMK-3 and CMK- 8 can be used which are infiltrated with siliceous polymeric precursors. 
Using this strategy, several ceramics such as $\mathrm{SiC},{ }^{25} \mathrm{SiOC},{ }^{26}$ $\mathrm{SiCN}^{26,27}$ and $\mathrm{SiCBN}^{28}$ have been obtained. Shi and co-workers demonstrated that in the case of ammonia treatment $\mathrm{SiC}-\mathrm{C}$ composites can be transformed into SiCN. ${ }^{26}$

$C N_{\mathrm{x}}$ materials. $\mathrm{C}_{3} \mathrm{~N}_{4}$ has been a hot topic for many years, especially as a high performance analogue ceramic of $\mathrm{Si}_{3} \mathrm{~N}_{4}$. However, in many precursor derived $\mathrm{CN}_{x}$-materials, the local chemistry is ill defined and the materials should be regarded as nitrogen rich carbons with predominately $\mathrm{sp}^{2}$-hybridized carbon and nitrogen atoms. The interest in porous $\mathrm{CN}_{x}$-materials comes from the knowledge of nitrogen substitution effects in activated carbons introducing beneficial functional groups for base catalysis, metal coordination, enhanced $\mathrm{CO}_{2}$-adsorption, and enhanced electrochemical activity in double layer capacitors.

The synthesis of carbon nitride with pores in the nanoscale was first reported by Vinu et al. in 2005 by polymerizing ethylenediamine (EDA) and carbon tetrachloride (CTC) within the mesopore channels. Recently also cyanamide melts were used to obtain highly ordered mesoporous $\mathrm{CN}_{x}$ structures (Fig. 7B). ${ }^{29}$ However, $\mathrm{CN}_{x}$ materials are not real carbides and are only mentioned in passing in this review.

Boron carbide based materials. Recently, BCN with an ultrahigh surface area was reported by Portehault et al..$^{30}$ They used a graphitic mesoporous carbon nitride as sacrificial template and a borane-tert-butylamine complex as boron source. The substitution reaction between carbon and boron as well as the nitrogen donor function of the $\mathrm{C}_{3} \mathrm{~N}_{4}$ led to a structural copy of the template material. It has been shown that the pyrolysis temperature is crucial for a high surface area, since it reaches a value of $1560 \mathrm{~m}^{2} \mathrm{~g}^{-1}$ for materials pyrolysed at $1673 \mathrm{~K}$ compared to $36 \mathrm{~m}^{2} \mathrm{~g}^{-1}$ for those treated at $823 \mathrm{~K}$. The high amount of microporosity is predominantly contributed to the elimination of carbon nitride residues. Not only carbons but also silica templates (SBA-15) have been used for nanoporous $\mathrm{BC}$ syntheses. Kaskel et al. recently synthesized nanoporous, nitrogen-free $\mathrm{B}_{4} \mathrm{C}$ via nanocasting (Fig. 7C). They used bis(decaboranyl)hexane, a precursor with the desired boron to carbon ratio of 4 . Infiltration into SBA-15 and KIT-6 templates and subsequent pyrolysis resulted in ordered mesoporous $\mathrm{B}_{4} \mathrm{C}$ ceramics with surface areas of up to $778 \mathrm{~m}^{2} \mathrm{~g}^{-1}$. 31

Transition metal based carbides. Mesoporous tungsten carbide was first described by Shi et al. using KIT-6 as a template (Fig. 7D).$^{32}$ Because of the volatility of the phosphotungstic acid it was necessary to press the "filled" KIT-6 for the purpose of closing the pore entrances and keeping the precursor within the pore network. In comparison to non-compacted references the surface area could be increased from 56 to $138 \mathrm{~m}^{2} \mathrm{~g}^{-1}$ and an improved cubic ordering was observed.

3.2.2 Soft templating approaches. Similar as in hard templating routes described above, where rigid solids (mainly oxides or carbons) are used as cast for the preparation of porous ceramics, soft templating approaches (STA) can efficiently be used for the introduction of well defined nanoporosity in hard ceramics (Fig. 8). However, a more sophisticated adjustment of template molecular structure and the precursor chemistry is

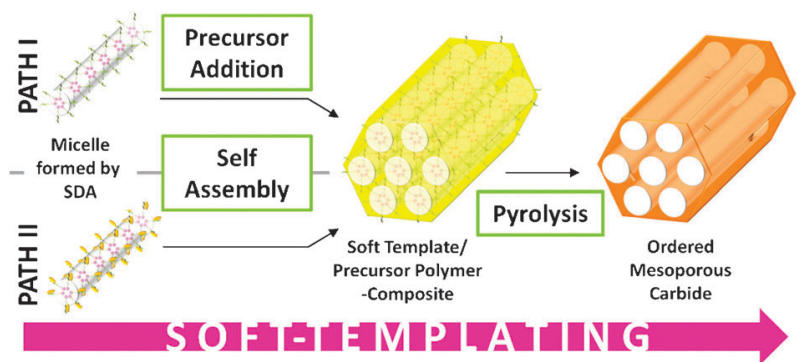

Fig. 8 Ordered mesoporous carbides synthesized by soft templating approaches.

needed. The aspired future pore structure must be directed by a soluble structure directing agent (SDA). It is the interplay of non-covalent, attractive and repulsive forces (mostly weak interactions e.g. van der Waals and Coulomb interactions) between the SDA molecules which causes their self-assembly. These self-assembled structures are used as templates for the construction of the desired materials, which are mostly obtained by polymerization of inorganic precursors around these SDAs. The structure directing agents are amphiphilic molecules, which are either cationic, anionic or non-ionic surfactants (mainly block co-polymers). Via this soft templating approach (STA) usually porous materials are synthesized having ordered arrangements of pores. The understanding of this system is predominantly related to the discovery of ordered mesoporous, siliceous materials at the beginning of the 1990s. For further details please see the review written by Zhao et al. ${ }^{33}$ In contrast to hard templating approaches, the STA imperatively requires the compatibility between the SDA template and the inorganic preceramic precursor. If this is not provided, macro phase separation would occur and no ordered structures can be obtained. Two different strategies are pursued. On one hand the inorganic precursor is connected to the organic block co-polymer covalently (Fig. 8B). After selfassembly of this hybrid polymer, the inorganic part is crosslinked and converted to the ceramic, while simultaneously the organic structure directing part is combusted. Thus the ordered structure of the SDA is converted into the ordered pore system of an inorganic material. On the other hand the SDA and the inorganic precursor are used separately and pass a co-assembly if both are compatible to each other (Fig. 8A). Analogously to the first pathway, the SDA-inorganic precursor composite is converted to a ceramic with an ordered pore arrangement. The latter technique is further subdivided into aqueous solution syntheses and evaporation induced self-assemblies (EISA). The EISA approach is particularly suitable for thin film preparation. The initial situation of an EISA synthesis is a sol of an uncondensed inorganic precursor and a structure directing agent. Due to the evaporation of the solvent, the SDA concentration increases until the critical micelle concentration (CMC) is exceeded and micelles start to form. Only after complete evaporation, known as the modulable steady state period (MSS), the final mesostructure is established due to the organization of the hybrid intermediates. The MSS strongly depends on different processing parameters, like the relative humidity and can last from a few seconds to several hours. At the end, the inorganic network is completely condensed and the hybrid mesostructure is stabilized. A main advantage is the larger variability of 
solvents, compared to the restricted aqueous sol gel approaches. Hence a great variety of ordered porous ceramics are accessible.

Silicon carbide based materials. Recently, this EISA approach has been used to synthesize silicon(oxy)carbide/carbon composite materials by using tetraethyl orthosilicate (TEOS) and resin (polymer of phenol and formaldehyde) as ceramic precursors in a co-assembly with the triblock co-polymer Pluronic F127. Resulting ceramics exhibit specific surface areas of up to $900 \mathrm{~m}^{2} \mathrm{~g}^{-1}$ as well as ordered and narrow distributed mesopores of approximately 4 to $6 \mathrm{~nm}$ in diameter. ${ }^{34}$

For certain applications the average pore sizes of the ceramics are crucial. The soft templating approach is a very adjuvant method to tune the porosity by simply varying the SDA. For this purpose mesostructured $\mathrm{SiC}$ materials were synthesized via hybrid sol-gel synthesis of glucose, TEOS and different alkyloxysilanes $\left(\mathrm{R}-\mathrm{Si}(\mathrm{OMe})_{3}\right)$. It was demonstrated that the alkyl chain length has a significant influence on the specific surface area and the pore diameter. By enlarging the alkyl chain length from $\mathrm{R}=$ methyl to $\mathrm{R}=n$-octyl the surface area increases from 151 to $345 \mathrm{~m}^{2} \mathrm{~g}^{-1}$ and the average pore size can be reduced from 18 to $5.7 \mathrm{~nm}^{35}$

These strategies have in common that the final ceramic is formed by carbothermal reduction of the in situ generated oxidic intermediate. Unfortunately, carbothermal reductions usually take place at high temperatures around $1795 \mathrm{~K}$. This is often attended by the collapse of the ordered structure and a decreasing porosity. To overcome this problem, single source polymer derived ceramic precursors are used. Wiesner et al. described the synthesis of ordered mesoporous SiCN materials with a hexagonal arrangement of pores via an EISA approach by using a commercial poly(ureamethylvinyl)silazane precursor (Ceraset). ${ }^{36}$ The obtained $\mathrm{SiCN}$ ceramics are stable up to $1773 \mathrm{~K}$ and exhibit a specific surface area of $38 \mathrm{~m}^{2} \mathrm{~g}^{-1}$. In analogy, porous $\mathrm{SiC}$ and $\mathrm{SiCN}$ with well-ordered mesopores were synthesized by Kim et al. In an elegant synthesis pathway, they tied polystyrene to a polycarbosilane unit in order to form a hybrid organic-inorganic block co-polymer. After thermal conversion these ordered mesoporous $\mathrm{SiC}^{37}$ and $\mathrm{SiCN}^{38}$ materials exhibit remarkable specific surface areas of 1325 and $428 \mathrm{~m}^{2} \mathrm{~g}^{-1}$, respectively.

Most of the discussed porous ceramics have ordered pore symmetries. However, a significant number of porous carbides with a more irregular pore network were reported, too. Recently, it has been found that microemulsions (particularly inverse microemulsions) are suitable to obtain porous carbides. In an inverse microemulsion aqueous nanodroplets are homogenously dispersed in an oil phase containing a preceramic precursor. The aqueous droplets are stabilized by a surfactant and can easily be tailored by changing the water to surfactant ratio $\left(R_{\mathrm{w}}\right)$. The preceramic precursor is then cross-linked either induced by thermal treatment or by using noble metal catalysts. The first valuable effect is that resulting pores in the obtained cross-linked polymer correspond to the former micelles and can therefore easily be tailored in size. The second feature is that these nanodroplets can serve as nanoreactors for the growth of nanoparticles, which hence are incorporated in situ into the generated porous ceramic. This approach was especially demonstrated for $\mathrm{CeO}_{x}$ containing $\mathrm{SiC}$ ceramics for catalytic applications. ${ }^{39}$ Highly porous silicon carbides with surface areas of up to $240 \mathrm{~m}^{2} \mathrm{~g}^{-1}$ incorporate catalytically active, nanosized $\mathrm{CeO}_{x}$ particles of 2 to $10 \mathrm{~nm}$ in size, corresponding to the adjusted $R_{\mathrm{w}}$ value. Porosity was even increased if platinum precursors were added to the water phase of the microemulsion. Platinum induces the cross-linking of the polycarbosilane precursor, which yields in extremely high surface areas for the obtained polymer $\left(992 \mathrm{~m}^{2} \mathrm{~g}^{-1}\right)$ as well as high surface areas for the final $\mathrm{SiC}$ ceramic $\left(423 \mathrm{~m}^{2} \mathrm{~g}^{-1}\right){ }^{40}$ Furthermore, this nanoparticle incorporation leads to impressive activities in different catalytic test reactions like total or partial methane oxidation.

The emulsion approach is versatile, since the amount of inner aqueous phase can be increased dramatically to volume ratios of more than 0.74 , leading to the formation of high internal phase emulsions (HIPEs). This is another very useful approach to obtain especially macroporous materials. If the continuous phase is polymerized, the shape of the prior water phase can be conserved as pores resulting in a PolyHIPE. Recently, macroporous silicon carbides were manufactured by using a liquid polycarbosilane precursor and divinylbenzene as the oil phase and subsequent pyrolysis. Resulting materials have characteristic spherical cells of $\sim 2 \mu \mathrm{m}$, interconnected by windows of $\sim 200 \mathrm{~nm}$ as well as a monolithic shape. Specific surface areas of up to $167 \mathrm{~m}^{2} \mathrm{~g}^{-1}$ are obtained (Fig. 9). ${ }^{41}$

Transition metal based carbides. Titanium carbide/carbon composite materials have been synthesized via an EISA approach by Zhao et al. They used titanium citrate or $\mathrm{TiCl}_{4}$ and resin as ceramic precursors in a co-assembly with the triblock co-polymer pluronic F127. ${ }^{42,43}$ Obtained materials exhibit narrowly distributed mesopores with hexagonal pore symmetry. Analogous results were achieved by using ammonium metatungstate instead of titanium citrate in order to synthesize ordered mesoporous WC/C composites. ${ }^{44,45}$

3.2.3 Template free approaches. Concerning the resource management, a template-free synthesis of porous carbides seems desirable because no chemicals have to be employed apart from those containing the required elements. Furthermore, many precursors undergo volume shrinkage during heat treatment and therefore are not suitable for template methods. However, the template free strategy is very challenging because

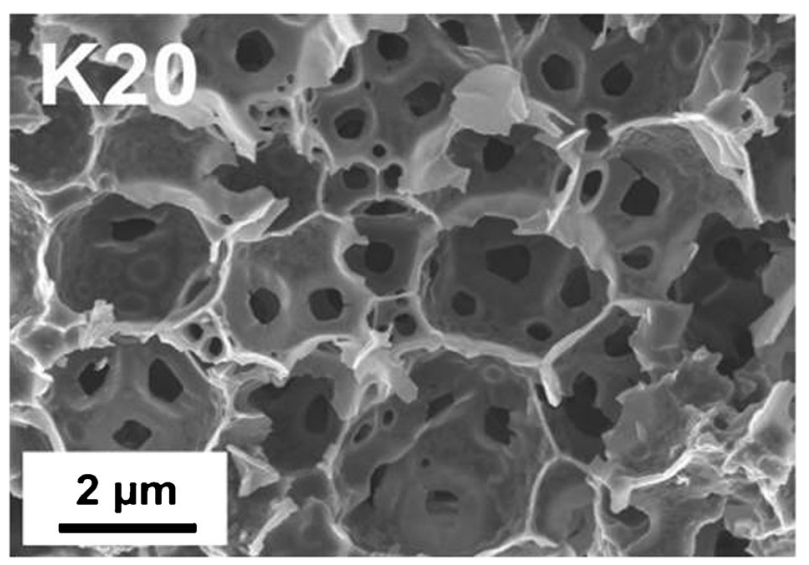

Fig. 9 SEM image of macroporous SiC derived from a HIPE approach. ${ }^{41}$ 
of the possible collapse of porous intermediate structures. However, some of these syntheses are presented in the literature for nanoporous materials, although this strategy is of higher significance for cellular ceramics. The formation of gels containing the needed elements and their transfer to carbides as well as the insertion of missing elements into already nanoporous materials were performed. In addition, the introduction of porosity due to gaseous by-products acting as a kind of foaming agent in the nanoscale is possible. Present efforts either address the synthesis of new materials or improve economic efficiency.

Silicon carbide based materials. The use of binary carbonaceous silicon xerogels was published by Jin and Guo. ${ }^{46,47}$ Resin, tetraethyl orthosilicate (TEOS) and nickel nitrate formed sols in ethanol. Further addition of hexamethylenetetramine led to gelation followed by in situ carbothermal reduction at $1523 \mathrm{~K}$. By varying the nickel amount the pore size could be adjusted from 3.5 to $45 \mathrm{~nm}$. The surface areas are as high as $204 \mathrm{~m}^{2} \mathrm{~g}^{-1}$. Porous silicon carbide films on Si substrates were produced via chemical vapour deposition $(\mathrm{CVD})$ of $\mathrm{Sn}\left(\mathrm{SiMe}_{3}\right)_{4}$. This method forms $\mathrm{Sn}$ particles embedded in an amorphous $\mathrm{SiC}_{1+x}$ film. The removal of the tin nanoparticles resulted in mesoporous silicon carbide with pores in the range from 10 to $100 \mathrm{~nm}$.

Transition metal based carbides. A template free route resulting in porous titanium carbide films was reported by Mullins et al. ${ }^{48}$ Reactive ballistic deposition of metallic titanium on a silicon wafer at $308 \mathrm{~K}$ in an ethylene atmosphere led to $\mathrm{TiC}$ with a surface area of $840 \mathrm{~m}^{2} \mathrm{~g}^{-1}$.

\subsubsection{Post synthetic insertion of porosity}

Metal extraction (carbide-derived carbons). When pure silicon was not abundantly available at the beginning of the last century, mainly silicon carbide was used in a reaction with hot chlorine gas as a basic material for the synthesis of $\mathrm{SiCl}_{4}$ (eqn (5)).

$$
\mathrm{SiC}(\mathrm{s})+2 \mathrm{Cl}_{2}(\mathrm{~g}) \stackrel{\Delta}{\rightarrow} \mathrm{SiCl}_{4}(\mathrm{~g})+\mathrm{C}(\mathrm{s})
$$

Later it was realized that the carbonaceous by-product was also worth to be noticed. This new class of highly porous carbon was named "mineral carbons" and meanwhile is widely known as carbide-derived carbon (CDC). Nowadays, $\mathrm{SiCl}_{4}$ is primarily synthesized from pure silicon by chlorination. But the carbon products formed according to eqn (5) received considerable attention and in recent years $\mathrm{CDC}$ materials have been synthesized from a wide range of binary carbides like $\mathrm{B}_{4} \mathrm{C}$, $\mathrm{SiC}, \mathrm{TiC}, \mathrm{VC}, \mathrm{WC}, \mathrm{ZrC}$ or ternary carbides like $\mathrm{Ti}_{3} \mathrm{AlC}_{2}, \mathrm{Ti}_{3} \mathrm{SiC}_{2}$, as well as from nitrides and carbonitrides. A very detailed review article about the structure, genesis, properties and applications of CDC materials in general was written by Presser et al. ${ }^{49}$ The most general equation for the synthesis of CDCs is eqn (6). The etching agents $\mathrm{X}$ can be gaseous halogens such as $\mathrm{Cl}_{2}, \mathrm{Br}_{2}, \mathrm{~F}_{2}, \mathrm{I}_{2}$ or halogen containing agents $\left(\mathrm{HCl}, \mathrm{HF}, \mathrm{XeF}_{2}\right.$, etc.). The most established etchant however is chlorine gas.

$$
\mathrm{aMC}(\mathrm{s})+\frac{b}{2} \mathrm{X}_{2}(\mathrm{~g}) \stackrel{\Delta}{\rightarrow} \mathrm{M}_{a} \mathrm{X}_{b}(\mathrm{~g})+\mathrm{aC}(\mathrm{s})
$$

The reaction from eqn (6) can be understood as a selective removal of metal atoms out of a metal carbide matrix. An enormous amount of porosity is generated under the conservation

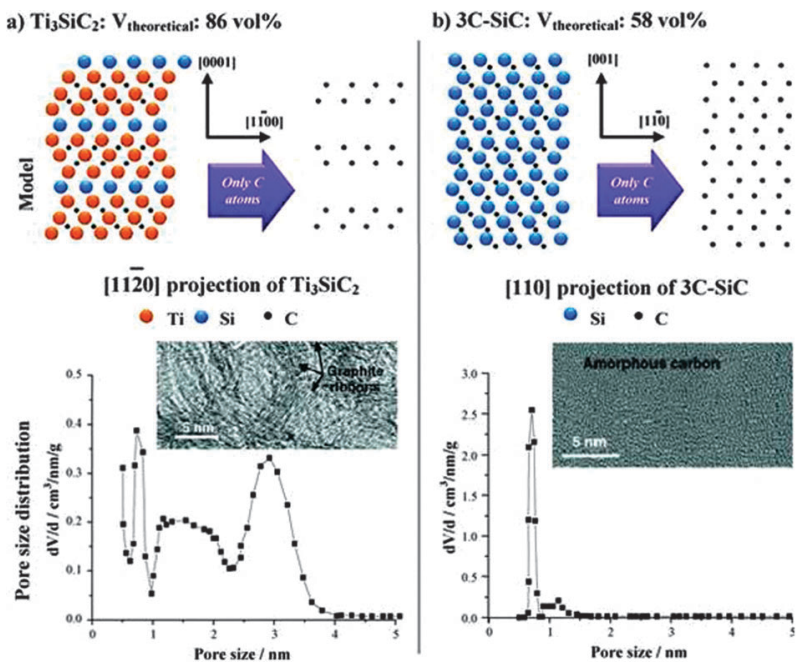

Fig. 10 Influence of the carbide structure on the porosity of the corresponding carbide derived carbon, ${ }^{49}$ pictures are reprinted with permission from ref. 49.

of the original shape of the carbide precursor and the control over the resulting pore sizes.

A bulk porosity of $>50 \%$ and a specific surface area of up to $3200 \mathrm{~m}^{2} \mathrm{~g}^{-1}$ are reported for CDC materials. Both largely depend on the structure of the used carbide material. As illustrated in Fig. 10, exemplarily for the ternary carbide $\mathrm{Ti}_{3} \mathrm{SiC}_{2}$ and the binary $3 \mathrm{C}$-SiC, the different distribution of carbon atoms in the carbide crystal lattice leads to different total porosities. $\mathrm{Ti}_{3} \mathrm{SiC}_{2}-\mathrm{CDC}$, which has a layered arrangement of carbon atoms, exhibits a way larger porosity than $\mathrm{SiC}-\mathrm{CDC}$, where carbon atoms are arranged in a zinc blende structure. If $\mathrm{Ti}_{3} \mathrm{SiC}_{2}$ and $\mathrm{SiC}$ are compared with regard to the predetermined position of carbon atoms in the resulting CDCs, also different grades of graphitization are obtained.

For the creation of larger pores or even the insertion of hierarchical porosity, templating techniques are suitable. Ordered mesoporous carbides are obtained using a nanocasting approach, as precursors for the synthesis of hierarchical CDCs with a narrow distributed, ordered mesopore architecture. ${ }^{50,51}$

It is characteristic for the CDC process that the shape of the carbide preforms can be maintained. For example $\mathrm{SiC}$ fibres ${ }^{52}$ or even more complex structures like mesoporous silicon carbides with a 2D-hexagonal or 3D-cubic ordered pore arrangement can be converted to the corresponding ordered CDCs under conservation of the former nanostructure (Fig. 11). ${ }^{50,51}$

Applications for these highly porous carbons are promising. They may be used as materials in gas storage, as filter materials, as protein adsorbing agents, in catalysis and first of all as electrode materials for supercaps and Li ion batteries as discussed in the following.

\section{Applications}

Due to the high chemical and thermal stability applications of porous carbides are widespread. The following paragraphs only represent a selection of applications collected by the authors. Those examples should represent the most recent and promising investigations. 


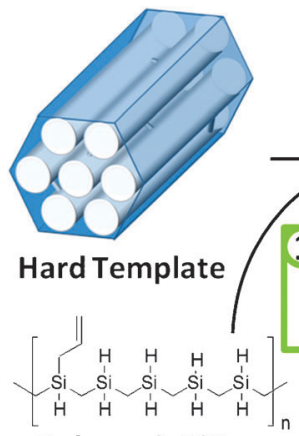

Polymeric SiC-

Precursor SMP-10

Carbide-derived

Carbon n
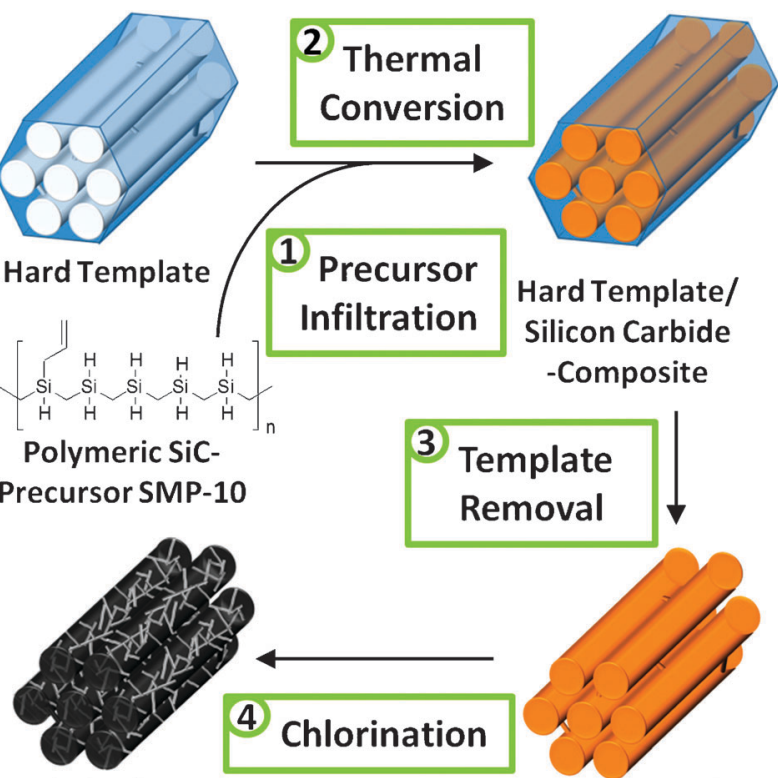

Template moval

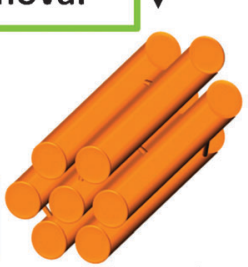

Replicated Silicon Carbide
Fig. 11 Synthesis of ordered mesoporous carbide derived carbons.

\section{Filtration and membranes}

Diesel engines emit harmful carcinogenic particulate matter due to the presence of polycyclic aromatic hydrocarbons as well as to their respirable particle size of about 10-20 nm for primary particles and 50-150 nm for agglomerates. To control the particulate emission diesel particulate filters were developed. One of the most promising filter materials is silicon carbide due to the good thermal conductivity and high temperature stability. Such filters are typically honeycomb wall flow filters made of sintered powders. ${ }^{53}$ Alternate plugging of the channels at the frontside and backside forces the gas to pass through the porous channel wall (Fig. 12). High filtration efficiency and low pressure drop are needed for an ecological and economical operation of the diesel engine. Therefore, filter systems with a mean pore size of 10-20 $\mu \mathrm{m}$ at a porosity of $40-60 \%$ are commonly used. By adding a $20 \mu \mathrm{m}$ thin silicon carbide membrane on the filter wall Hiroshi et al. were able to increase the filtration efficiency. ${ }^{54}$ For a low pressure drop, mainly influenced by the amount of deposited particulate matter, periodical removal by burning the particulate off at about $600{ }^{\circ} \mathrm{C}$ is necessary. To lower the temperature for the particulate oxidation and hence the thermal stress of the filter material catalysts, ${ }^{55}$ mainly metal oxides are coated on the supporting silicon carbide.
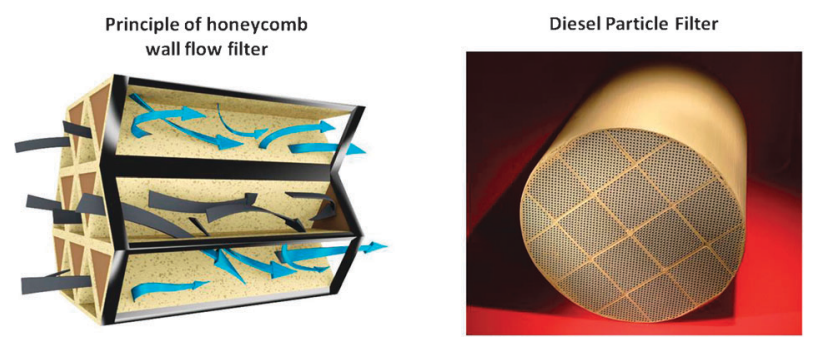

Fig. 12 Left: design and working principle of a honeycomb wall flow filter (courtesy: CleanDieselCeramics $\mathrm{GmbH}$ ); right: segmented $\mathrm{SiC}$ filter (source: Fraunhofer-IKTS).
Silicon carbide seems to be a promising material for high temperature and steam stable membranes and was described by Tsotsis et al. ${ }^{56}$ Membranes synthesized by this group exhibited a good stability against steam and allowed the separation of hydrogen from nitrogen. They suggested that those systems could be used as separators in steam reforming reactors to remove hydrogen from the product stream enhancing the conversion of methane.

\section{Combustion environment and burner applications}

Ceramic foams are widely used for porous burners. The combustion of fuel/air mixtures in porous media shows a lot of advantages compared to conventional combustion processes. The very intensive heat transport inside the porous structure leads to higher burning rates, increased flame stability with low noise emissions, and controllable, homogeneous combustionzone temperatures which lead to a reduction in $\mathrm{NO}_{x}$ and $\mathrm{CO}$ emissions.

According to the application, porous structures must resist thermo-mechanical stress caused by high temperature gradients. Furthermore, the materials must be adjusted to the specific operational conditions like maximum temperature or corrosion by aggressive flue gases and water vapour. Generally, foam structures are useful for burner applications. Regarding to other porous components like static mixer structures and wire meshes they feature good conductive heat-transport, a rather long start up phase due to lower macroporosity, intermediate radiative heat-transport properties, intermediate dispersion properties, and moderate pressure drop. There are several ceramic materials like $\mathrm{Al}_{2} \mathrm{O}_{3}$ and $\mathrm{ZrO}_{2}$ (high temperature stability in oxidizing environments) which have interesting properties for burner applications. However, with the specified requirements $\mathrm{SiC}$ is the best compromise between operating temperature, corrosion resistance, thermal conductivity and thermal shock resistance. ${ }^{57}$

The most common method used to produce open cell ceramic foams for technical applications is the replica technique (path I). For burner applications different open-celled $\mathrm{SiC}$ materials like pressure less sintered $(\mathrm{SSiC})$, reaction bonded silicon infiltrated $(\mathrm{SiSiC})$ and nitride bonded silicon carbide (NBSiC) are under investigation.

$\mathrm{SiSiC}$ open celled forms are commonly employed as active zone in porous burners for heat radiation application. The manufacturing of the ceramic foams is based on a casting of commercially available polyurethane foams with $\alpha$-SiC powder slurries. After pyrolysis a silicon melt infiltration is used to obtain the final $\mathrm{SiSiC}$ ceramic with a reaction bonded $\beta-\mathrm{SiC}-\mathrm{Si}$ matrix which binds the dispersed $\alpha$-SiC powder. Typically, the resulting ceramic foams have an open porosity of $>87 \%$. An aging of the materials in a combustion atmosphere of methane burners leads to the formation of a silica layer on the surface of the ceramic struts. Beside this, no significant variations of the ceramic were detected during aging up to $1000 \mathrm{~h} .^{58}$

The thermal stability of $\mathrm{SiSiC}$ is limited by the melting point of silicon. Operating temperatures above $1400{ }^{\circ} \mathrm{C}$ lead to an out-melting of the free silicon from the struts. Dense pressure-less sintered silicon carbide ( $\mathrm{SSiC}$ ) shows a very high temperature and chemical stability, although the high amount of strut porosity of standard SSiC foams is related to material degradation by inner 
oxidation in combustion atmospheres. To improve the oxygen resistance of $\mathrm{SSiC}$, foams with reduced inner porosity have been developed which show reduced oxygen rates in burner rig tests. A further reduction of the strut porosity will allow SSiC to be used in long-term applications such as in afterburners of solid oxide fuel cell (SOFC) systems. ${ }^{59}$

Porous NBSiC structures were produced from a mixture of $\mathrm{SiC}$, $\mathrm{Si}$ powder and polysiloxanes as preceramic polymers. During the heat treatment in nitrogen or ammonia atmosphere the decomposition of the preceramic polymer takes place to form $\mathrm{Si}-\mathrm{O}-\mathrm{C}$ phases and at higher temperatures the nitridation of $\mathrm{Si}$ to $\mathrm{Si}_{3} \mathrm{~N}_{4}$ and $\mathrm{Si}_{2} \mathrm{~N}_{2} \mathrm{O}$ proceeds. Under inert atmosphere $\mathrm{NBSiC}$ is stable up to $1550{ }^{\circ} \mathrm{C}$. Above this temperature the decomposition of $\mathrm{Si}_{3} \mathrm{~N}_{4}$ and re-crystallization of $\mathrm{SiC}$ are initiated. The designated application temperature for NBSiC foams from this preparation method in oxygen containing atmospheres is below $1400{ }^{\circ} \mathrm{C} .{ }^{60}$

\section{Solar absorber}

Cellular ceramic materials are applicable as absorbers in volumetric solar receivers. ${ }^{61,62}$ Volumetric receivers are used in the solar tower technology and convert solar radiation into high-temperature heat. In this process the cellular ceramics are heated by absorption of concentrated solar radiation and transfer the energy to a gaseous fluid, like ambient air which flows through the cellular structures. The cellular materials must have a high porosity and cell density to allow the concentrated solar radiant to penetrate into the volume of the cellular material and to achieve large surface areas for an effective heat transfer from the solid material to the gaseous fluid. Further material requirements are high optical absorption in the wavelength range of the solar spectrum as well as high thermal conductivity and temperature stability to resist operation temperatures and hot spots of more than $1000{ }^{\circ} \mathrm{C}$. Due to its favourable heat and heat shock resistance properties, $\mathrm{SiC}$ is a promising material to fulfill the requirements of the application as a solar absorber.

Different highly porous SiC structures like extruded and 3D printed honeycombs, ceramic foams and fiber mesh materials have been tested and have been evaluated with the objective to develop solar absorbers. Based on their high specific surface area and excellent absorption and permeability properties solar absorbers with high efficiencies were achieved by fiber mesh materials and foams with high cell densities. However, operating these materials at higher temperatures causes oxidation problems. Honeycomb structures have shown lower efficiency but higher durability and corrosion resistance. ${ }^{63}$

In solar tower technology, the heat energy is e.g. used to generate steam for conventional steam turbine processes. Further applications for porous ceramic solar absorbers are solar chemical reactors, which allow thermochemical storage of solar energy. This reactor concept employs ceramic supports, that are coated with catalysts capable to perform "solar-aided" reactions, e.g. for the production of hydrogen by water splitting or natural gas reforming. ${ }^{64}$

\section{Catalysis}

The role of porous carbides in catalysis is important in two ways, namely as catalyst supports and as catalysts itself because of the intrinsic activity of some of the transition metal carbides. The main advantage of several carbides as catalyst supports compared to oxide systems is their high-temperature stability as well as their higher thermal conductivity. Whereas cellular materials allow high flow velocities with small pressure drops in combination with a high mass and heat transfer rate, ${ }^{65}$ nanoporous supports provide the advantage of high surface areas and therefore the possibility to highly disperse active species. Recently, Pham-Huu et al. demonstrated that the use of cobalt catalysts supported on a $\mathrm{SiC}$ foam is favourable in Fischer-Tropsch synthesis compared to $\mathrm{Al}_{2} \mathrm{O}_{3}$ supports. ${ }^{66}$ The selectivity to the desirable $\mathrm{C}_{5}$ fraction could be increased from $54 \%$ for $\mathrm{Al}_{2} \mathrm{O}_{3}$ to $80 \%$ for $\mathrm{SiC}$. They pointed out that these results are caused by the avoidance of hot spots due to the higher thermal conductivity of $\mathrm{SiC}$. Hot spots facilitate secondary cracking reactions and therefore the production of lighter hydrocarbons.

Nanoporous $\mathrm{SiC}$ supports were further described in the oxidative dehydrogenation of propane, ${ }^{35}$ the $\mathrm{CO}$ oxidation ${ }^{67}$ and the direct oxidation of butane to maleic anhydride (Fig. 13). ${ }^{68}$ The investigations with respect to the propane dehydrogenation and $\mathrm{CO}$ oxidation have in common that the thermal conductivity of the support plays a crucial role and avoids the formation of hot spots during these exothermic reactions. The synthesis of nanoporous $\mathrm{SiC}$ functionalized with $\mathrm{Pt}$ and $\mathrm{CeO}_{2}$ nanoparticles was published by Kaskel et al. ${ }^{40}$ Those systems afford high activities in methane oxidation. To summarize, the thermal conductivity and high-temperature stability of cellular as well as nanoporous carbides and nitrides make those materials profitable compared with oxide supports.

Besides the use as catalyst supports the intrinsic catalytic activity of nanoporous carbides has also been described. Tungsten carbide and carbon nitride have shown activity in several test reactions. Decomposition of ammonia was performed by Shi and co-workers and yielded complete conversion to hydrogen and nitrogen at $773 \mathrm{~K}$ and therewith a lowering of $80 \mathrm{~K}$ compared to the non-mesoporous reference. ${ }^{32}$

\section{Gas storage}

Nanoporous carbides are discussed as materials for gas storage due to their high surface area. Ha et al. performed hydrogen storage measurements on 3D-ordered mesoporous carbon
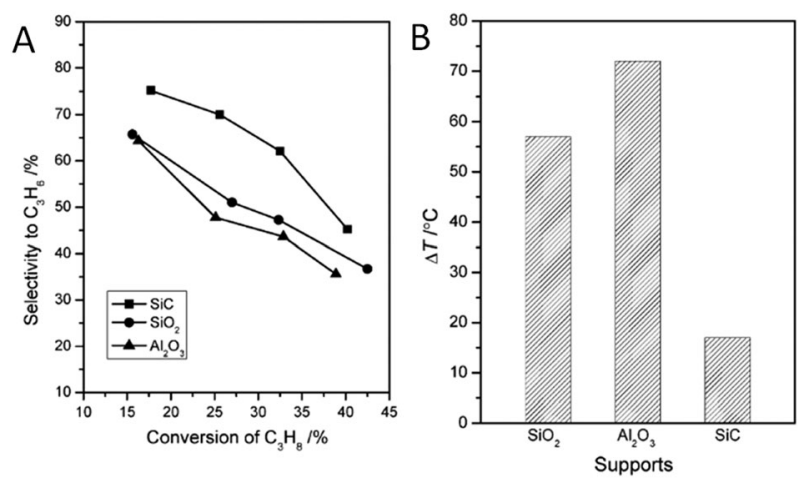

Fig. 13 Influence of the chosen support on the results of the propane oxidative hydrogenation (A) and the difference between the set and bed temperature (B), pictures are reprinted with permission from ref. 35 . 
nitride. ${ }^{29}$ These $\mathrm{C}_{3} \mathrm{~N}_{4}$ materials only show a little hydrogen uptake of $0.25 \mathrm{wt} \%$ at 50 bar. $\mathrm{H}_{2}$ uptake of up to $1.07 \mathrm{wt} \%$ ( $77 \mathrm{~K}, 1$ bar) could be realized for boron carbon nitrides by the Portehault group. ${ }^{30}$ They further pointed out that not only the micropore volume but also the chemical environment influences the hydrogen uptake as they investigated boron carbon nitrides treated at temperatures between $1073 \mathrm{~K}$ and $1673 \mathrm{~K}$.

Very recently, mesoporous carbides have been transformed to carbon by removing the metal atoms via chlorination. Obtained materials are highly suitable for gas storage applications because they offer meso- and microporosity at the same time. Such ordered mesoporous carbide-derived carbons (CDCs) show hydrogen capacities of $50.9 \mathrm{mg} \mathrm{g}^{-1}$ at 40 bar. $^{50,69}$ Likewise methane and $n$-butane adsorption measurements were performed showing impressive adsorption properties.

\section{Electrochemical applications}

Li-ion batteries. Due to a very high energy density, a high operating voltage window and a low self-discharge, the Li-ion battery is the most widely used secondary battery system in present days. With respect to the miniaturization call in the electrical vehicle, military and portable device industry, there is a huge effort to further optimize and increase the specific capacity and the energy density of Li-ion batteries. Particularly silicon was found to accommodate up to 4.4 atoms of lithium per silicon atom $\left(\mathrm{Li}_{22} \mathrm{Si}_{5}\right)$ which leads to ultra high insertion capacities of $4200 \mathrm{mAh} \mathrm{g}^{-1}$ but with low reversibility and a rapid capacity fade. The reason is cracking and disintegration of the electrode, as well as the loss of electronic conductivity due to the enormous volume change (over $400 \%$ from $\mathrm{Si}$ to $\mathrm{Li}_{22} \mathrm{Si}_{5}$ ) during alloying lithium into silicon. To overcome this and suppress volume expansion silicon was embedded in inactive matrices like $\mathrm{TiC}$, $\mathrm{TiN}$, or $\mathrm{SiC}$, which have high mechanical strength and serve as cushions. Furthermore porous $\mathrm{Si} / \mathrm{C}$ and $\mathrm{Si}(\mathrm{O}) / \mathrm{C}$ composites derived from polymers or via chemical vapour deposition ${ }^{70}$ have shown to successfully improve the capacity retention of $\mathrm{Li}$-ion anodes and provide larger reversible capacities than pure silicon anodes. A detailed review about this topic can be found elsewhere. ${ }^{71}$

Supercapacitors. Capacitive energy storage is used whenever high power densities or rapid energy recuperation is required. Supercapacitors, also known as electric double-layer capacitors (EDLC), store energy due to physical charge separation and hence show complete reversibility and long lifetimes. They have very high power densities but reduced energy densities as compared to Li-ion batteries. As the essential active material of a supercapacitor, the pore characteristic and nanostructure of the porous electrode determine the energy and power density characteristics. Carbon materials derived from various carbides, known as CDCs, have demonstrated to be promising supercap materials. ${ }^{49}$ Especially carbons derived from ordered mesoporous silicon carbides show impressive performances due to a hierarchical pore structure of micropores (formation of electric double layer) and mesopores (serving as electrolyte highways). Even at high current densities of $20 \mathrm{~A} \mathrm{~g}^{-1}$ only capacitance retentions of $85 \%$ occurred. $^{72,73}$

Methanol fuel cell. The development of new catalytically active materials for fuel cell technologies is one of the major challenges in a century of decreasing oil and coal deposits. The efficiency of hydrogen as well as methanol fuel cells usually depends on the noble metal catalysts like platinum or ruthenium. The main drawbacks of these catalysts are high costs and their sensitivity against $\mathrm{CO}$ or sulfidic poisoning. A potential alternative is tungsten carbide showing catalytic similarity to metals in the platinum group combined with advanced poisoning resistance. Recently, ordered macroporous $\mathrm{WC},{ }^{13}$ mesoporous $\mathrm{WC}^{45}$ as well as WC coated ordered mesoporous carbons ${ }^{74}$ were used as catalysts or catalyst supports for the oxygen reduction reaction (ORR) in proton exchange membrane fuel cells (PEMFCs) and direct methanol fuel cells. WC serves as independent catalyst and as promoter for the electrochemical activity of $\mathrm{Pt}$ catalysts. $\mathrm{Pt} / \mathrm{WC}$ co-catalysts show a larger activity compared to pure $\mathrm{Pt} / \mathrm{C}$ materials due to the synergetic effects of WC and Pt. ${ }^{74}$

Microbial fuel cells. Microbial fuel cells convert the energy of organic matter into electricity using the bioelectrocatalytic activity of microorganism. For that reason these devices are very promising in waste treatment combined with simultaneous power generation. There are different mechanisms how electron transfer from the microorganism to the electrode can be provided, reaching from direct electron transfer via bacteria pili or electron shuttling compounds to the use of energy rich metabolic products. The latter approach requires anodes which directly oxidize these metabolites. Again platinum exposes to be a highly active electrocatalyst, but with the disadvantage of being expensive and fragile against poisoning. Recently, tungsten carbide was found to overcome these problems, being a low cost, high performance electrocatalyst with good biocompatibility. Further information about microbial fuel cells can be found in another review. ${ }^{75}$

\section{Conclusion and outlook}

In the last decade, tremendous progress in tailoring the pore size of porous carbide materials has been achieved. A surface area as high as about $1000 \mathrm{~m}^{2} \mathrm{~g}^{-1}$ seems to be a limit reachable in this materials class. However, oxidation resistance is a limitation for such high surface area solids at least in oxidation catalysis, while under reducing conditions even at high temperature $\left(1000^{\circ} \mathrm{C}\right)$ a high textural stability can be seen as a strength of non-oxide solids.

From the preparation point of view precursor-derived materials offer a higher degree of freedom for attaining even hierarchical pore systems, however, relatively high cost of polymer-derived ceramics may still hamper to make economic use of such well defined pore systems. Moreover secondary structures such as agglomerates, spheres or even monoliths of mesoporous carbides need to be developed for practical applications.

Cellular SiC ceramics represent a more mature class of materials. However, since traditional particle-based processing routes typically lead to very large pore materials $(>10 \mu \mathrm{m})$ there is plenty of room in between, and especially at the level between $100 \mathrm{~nm}$ and $10000 \mathrm{~nm}$ innovations are needed to produce ordered pore systems or at least materials with a narrow pore size distribution. 
Porous $\mathrm{SiC}$ materials are only the beginning. The concepts developed for this relatively simple class of solids have to be adapted to transition metals and other elements to demonstrate the wide applicability of porous carbides. Further attention should also be turned to transition metal nitrides. Especially molybdenum and tungsten carbides and nitrides are promising catalytic materials if they are synthesized with high and well defined specific surface areas. Due to the highly oxygen sensitive surface, controlled passivation techniques are needed for precursor approaches generating the nitride catalyst inside the reactor followed by in situ testing and characterization. The examples discussed here are only a first glance on this rapidly developing field.

The latter is even more valid for carbide derived carbons. Precursor derived CDCs show extremely high specific surface areas of up to $3000 \mathrm{~m}^{2} \mathrm{~g}^{-1}$ and can be readily tailored in pore size distribution and surface functionalities. Given the widespread application of porous carbons in catalytic and electrochemical applications this field will rapidly expand. Certainly, the review presented here can only be a snapshot of the most recent research activities.

\section{Notes and references}

1 R. Riedel, I. W. Chen and Editors, Ceramics Science And Technology, Volume 2: Properties, Wiley-VCH Verlag GmbH \& Co. $\mathrm{KGaA}, 2010$.

2 H. Klemm, J. Am. Ceram. Soc., 2010, 93, 1501.

3 A. W. Weimer, K. J. Nilsen, G. A. Cochran and R. P. Roach, AIChE J., 1993, 39, 493.

4 P. Colombo, G. Mera, R. Riedel and G. D. Soraru, J. Am. Ceram. Soc., 2010, 93, 1805.

5 P. Colombo, Philos. Trans. R. Soc. London, Ser. A, 2006, 364, 109.

6 P. Colombo and H. P. Degischer, Mater. Sci. Technol., 2010, 26, 1145.

7 C. Zollfrank, R. Kladny, H. Sieber and P. Greil, J. Eur. Ceram. Soc., 2004, 24, 479.

8 C. Vakifahmetoglu and P. Colombo, Adv. Eng. Mater., 2008, 10, 256.

9 B.-H. Yoon, E.-J. Lee, H.-E. Kim and Y.-H. Koh, J. Am. Ceram. Soc., 2007, 90, 1753.

10 C. Vakifahmetoglu, P. Colombo, A. Pauletti, C. F. Martin and F. Babonneau, Int. J. Appl. Ceram. Technol., 2010, 7, 528.

11 K. Sonnenburg, P. Adelhelm, M. Antonietti, B. Smarsly, R. Noske and P. Strauch, Phys. Chem. Chem. Phys., 2006, 8, 3561.

12 C. Vakifahmetoglu, I. Menapace, A. Hirsch, L. Biasetto, R. Hauser, R. Riedel and P. Colombo, Ceram. Interfaces, 2009, 35, 3281.

13 J. P. Bosco, K. Sasaki, M. Sadakane, W. Ueda and J. G. Chen, Chem. Mater., 2009, 22, 966.

14 C. R. Rambo, J. Cao, O. Rusina and H. Sieber, Carbon, 2005, 43, 1174.

15 H. Sieber, C. Zollfrank, N. Popovska, D. Almeida and H. Gerhard, Key Eng. Mater., 2004, 264-268, 2227.

16 P. Krawiec, C. Schrage, E. Kockrick and S. Kaskel, Chem. Mater., $2008,20,5421$.

17 A. H. Lu and F. Schüth, Adv. Mater., 2006, 18, 1793.

18 Y. Shi, Y. Wan and D. Zhao, Chem. Soc. Rev., 2011, 40, 3854.

19 P. Krawiec, C. Weidenthaler and S. Kaskel, Chem. Mater., 2004, 16, 2869.

20 K.-H. Park, I.-K. Sung and D.-P. Kim, J. Mater. Chem., 2004, 14, 3436.

21 J. Yan, A. Wang and D.-P. Kim, J. Phys. Chem. B, 2006, 110, 5429.

22 A. H. Lu, W. Schmidt, W. Kiefer and F. Schüth, J. Mater. Sci., 2005, 40, 5091.

23 N. Leventis, A. Sadekar, N. Chandrasekaran and C. SotiriouLeventis, Chem. Mater., 2010, 22, 2790.
24 B. Zhao, H. Zhang, H. Tao, Z. Tan, Z. Jiao and M. Wu, Mater. Lett., 2011, 65, 1552.

25 X. Yuan, J. Lü, X. Yan, L. Hu and Q. Xue, Microporous Mesoporous Mater., 2011, 142, 754.

26 Y. Shi, Y. Wan, Y. Zhai, R. Liu, Y. Meng, B. Tu and D. Zhao, Chem. Mater., 2007, 19, 1761.

27 J. Yan, A. Wang and D.-P. Kim, Microporous Mesoporous Mater., 2007, 100, 128.

28 Q. D. Nghiem, H. I. Ryoo and D.-P. Kim, J. Korean Ceram. Soc., 2007, 44, 358.

29 S. S. Park, S.-W. Chu, C. Xue, D. Zhao and C.-S. Ha, J. Mater. Chem., 2011, 21, 10801.

30 D. Portehault, C. Giordano, C. Gervais, I. Senkovska, S. Kaskel, C. Sanchez and M. Antonietti, Adv. Funct. Mater., 2010, 20, 1827.

31 S. Kaskel, L. Borchardt, E. Kockrick, P. Wollmann, M. M. Guron, L. G. Sneddon and D. Geiger, Chem. Mater., 2010, 22, 4660.

32 X. Cui, H. Li, L. Guo, D. He, H. Chen and J. Shi, Dalton Trans., 2008, 6435.

33 Y. Wan, Y. Shi and D. Zhao, Chem. Commun., 2007, 897.

34 S. Dawes, USA Pat 7910082, March 22, 2011.

35 J. Xu, Y.-M. Liu, B. Xue, Y.-X. Li, Y. Cao and K.-N. Fan, Phys. Chem. Chem. Phys., 2011, 13, 10111.

36 M. Kamperman, C. B. W. Garcia, P. Du, H. Ow and U. Wiesner, J. Am. Chem. Soc., 2004, 126, 14708.

37 Q. D. Nghiem and D.-P. Kim, Chem. Mater., 2008, 20, 3735.

38 Q. D. Nghiem, D. Kim and D.-P. Kim, Adv. Mater., 2007, 19, 2351.

39 E. Kockrick, P. Krawiec, U. Petasch, H.-P. Martin, M. Herrmann and S. Kaskel, Chem. Mater., 2007, 20, 77.

40 E. Kockrick, R. Frind, M. Rose, U. Petasch, W. Bohlmann, D. Geiger, M. Herrmann and S. Kaskel, J. Mater. Chem., 2009, 19, 1543.

41 R. Frind, M. Oschatz and S. Kaskel, J. Mater. Chem., 2011, 21, 11936.

42 T. Yu, Y. H. Deng, L. Wang, R. L. Liu, L. J. Zhang, B. Tu and D. Y. Zhao, Adv. Mater., 2007, 19, 2301.

43 C.-H. Huang, D. Gu, D. Zhao and R.-A. Doong, Chem. Mater., 2010, 22, 1760.

44 R. Ganesan, D. J. Ham and J. S. Lee, Electrochem. Commun., 2007, 9, 2576.

45 Y. Wang, S. Song, P. K. Shen, C. Guo and C. M. Li, J. Mater. Chem., 2009, 19, 6149.

46 X.-Y. Guo and G.-Q. Jin, J. Mater. Sci., 2005, 40, 1301.

47 G.-Q. Jin and X.-Y. Guo, Microporous Mesoporous Mater., 2003, 60, 207.

48 D. W. Flaherty, N. T. Hahn, D. Ferrer, T. R. Engstrom, P. L. Tanaka and C. B. Mullins, J. Phys. Chem. C, 2009, 113, 12742.

49 V. Presser, M. Heon and Y. Gogotsi, Adv. Funct. Mater., 2011, 21, 810 .

50 M. Oschatz, E. Kockrick, M. Rose, L. Borchardt, N. Klein, I. Senkovska, T. Freudenberg, Y. Korenblit, G. Yushin and S. Kaskel, Carbon, 2010, 48, 3987.

51 P. Krawiec, E. Kockrick, L. Borchardt, D. Geiger, A. Corma and S. Kaskel, J. Phys. Chem. C, 2009, 113, 7755.

52 M. Rose, E. Kockrick, I. Senkovska and S. Kaskel, Carbon, 2009, 48, 403.

53 J. Adler, Int. J. Appl. Ceram. Technol., 2005, 2, 429.

54 O. Hiroshi, K. Preechar and H. Katsunori, Soc. Automot. Eng., [Spec. Publ.] SP, 2011, SP-2318, 177.

55 D. Fino, Sci. Technol. Adv. Mater., 2007, 8, 93.

56 R. J. Ciora, B. Fayyaz, P. K. T. Liu, V. Suwanmethanond, R. Mallada, M. Sahimi and T. T. Tsotsis, Chem. Eng. Sci., 2004, 59, 4957.

57 D. Trimis, O. Pickenaecker, K. Wawrzinek and Editors, Cellular Ceramics, Wiley-VCH Verlag GmbH \& Co. KGaA, 2005.

58 A. Ortona, S. Pusterla, P. Fino, F. R. A. Mach, A. Delgado and S. Biamino, Adv. Appl. Ceram., 2010, 109, 246.

59 A. Fuessel, D. Boettge, J. Adler, F. Marschallek and A. Michaelis, Adv. Eng. Mater., 2011, 13, 1008.

60 U. F. Vogt, L. Gyoerfy, A. Herzog, T. Graule and G. Plesch, J. Phys. Chem. Solids, 2007, 68, 1234.

61 T. Fend, R. Pitz-Paal, B. Hoffschmidt, O. Reutter and Editors, Cellular Ceramics, Wiley-VCH Verlag GmbH \& Co. KGaA, 2005.

62 T. Fend, Opt. Appl., 2010, 40, 271. 
63 C. C. Agrafiotis, I. Mavroidis, A. G. Konstandopoulos, B. Hoffschmidt, P. Stobbe, M. Romero and V. Fernandez-Quero, Sol. Energy Mater. Sol. Cells, 2007, 91, 474.

64 C. C. Agrafiotis, C. Pagkoura, S. Lorentzou, M. Kostoglou and A. G. Konstandopoulos, Catal. Today, 2007, 127, 265.

65 M. V. Twigg and J. T. Richardson, Ind. Eng. Chem. Res., 2007, 46, 4166.

66 M. Lacroix, L. Dreibine, T. B. de, F. Vigneron, D. Edouard, D. Begin, P. Nguyen, C. Pham, S. Savin-Poncet, F. Luck, M.-J. Ledoux and C. Pham-Huu, Appl. Catal., A, 2011, 397, 62.

67 X.-N. Shen, Y. Zheng, Y.-Y. Zhan, G.-H. Cai and Y.-H. Xiao, Mater. Lett., 2007, 61, 4766.

68 M. J. Ledoux, C. Crouzet, C. Pham-Huu, V. Turines, K. Kourtakis, P. L. Mills and J. J. Lerou, J. Catal., 2001, 203, 495.
69 E. Kockrick, C. Schrage, L. Borchardt, N. Klein, M. Rose, I. Senkovska and S. Kaskel, Carbon, 2010, 48, 1707.

70 A. Magasinski, P. Dixon, B. Hertzberg, A. Kvit, J. Ayala and G. Yushin, Nat. Mater., 2010, 9, 461.

71 U. Kasavajjula, C. Wang and A. J. Appleby, J. Power Sources, 2007, 163, 1003.

72 Y. Korenblit, M. Rose, E. Kockrick, L. Borchardt, A. Kvit, S. Kaskel and G. Yushin, ACS Nano, 2010, 4, 1337.

73 M. Rose, Y. Korenblit, E. Kockrick, L. Borchardt, M. Oschatz, S. Kaskel and G. Yushin, Small, 2011, 7, 1108

74 Q. Zhu, S. Zhou, X. Wang and S. Dai, J. Power Sources, 2009, 193, 495.

75 U. Schroeder, J. Solid State Electrochem., 2011, 15, 1481. 